\title{
Understanding vulnerability for depression from a cognitive neuroscience perspective: A reappraisal of attentional factors and a new conceptual framework
}

\author{
Rudi De RaEdT ANd ERnSt H.W. Koster \\ Ghent University, Ghent, Belgium
}

\begin{abstract}
We propose a framework to understand increases in vulnerability for depression after recurrent episodes that links attention processes and schema activation to negative mood states, by integrating cognitive and neurobiological findings. Depression is characterized by a mood-congruent attentional bias at later stages of information processing. The basic idea of our framework is that decreased activity in prefrontal areas, mediated by the serotonin metabolism which the HPA axis controls, is associated with an impaired attenuation of subcortical regions, resulting in prolonged activation of the amygdala in response to stressors in the environment. Reduced prefrontal control in interaction with depressogenic schemas leads to impaired ability to exert attentional inhibitory control over negative elaborative processes such as rumination, leading in turn to sustained negative affect. These elaborative processes are triggered by the activation of negative schemas after confrontation with stressors. In our framework, attentional impairments are postulated as a crucial process in explaining the increasing vulnerability after depressive episodes, linking cognitive and biological vulnerability factors. We review the empirical data on the biological factors associated with the attentional impairments and detail how they are associated with rumination and mood regulation. The aim of our framework is to stimulate translational research.
\end{abstract}

Major depressive disorder, one of the most common psychiatric disorders, is a recurrent problem for many people (Goodwin, Jacobi, Bittner, \& Wittchen, 2006). Although there are currently well-established cognitive/ behavioral (Hollon \& Dimidjian, 2009) and somatic (Gitlin, 2009) treatment options for depression, relapse or recurrence rate after remission or recovery remains very high. This indicates that current treatment options are insufficiently successful in identifying and diminishing underlying vulnerability.

Vulnerability can be conceptualized as a trait-like latent endogenous process reactive to the effects of stress, residing in genetic, biological, and psychological variables (Ingram \& Siegle, 2009). There is accumulating evidence for a kindling effect in depression, which means that after each episode people become more vulnerable to relapse or recurrence, because successive depressive episodes are triggered by progressively milder stressors (Monroe \& Harkness, 2005). The number of previous episodes is revealed in several studies (e.g., Kessing, Hansen, Andersen, \& Angst, 2004) to be among the strongest predictors of relapse or recurrence. All these data are in line with the idea that depressive episodes leave a "scar," which increases vulnerability to new episodes. Understanding underlying mechanisms of this increasing vulnerability to depression is of crucial importance to improving treatment.
To date, most vulnerability models have focused on either biological or psychological/cognitive processes, although recent research increasingly focuses on the interplay between cognitive and biological processes in depression. We aimed to develop a framework to understand the increasing vulnerability to depression, focusing on the interplay between cognitive and biological processes. Although many other cognitive processes, such as motivation and memory, may also be relevant to depression vulnerability, we propose a new conceptual framework, with mood-congruent attentional biases as the central process. In contrast to previously held ideas (Williams, Watts, MacLeod, \& Mathews, 1997), but in line with recent research, we argue that attentional factors are of crucial importance in understanding increasing vulnerability for depression. Attention is considered a central process, being directly related to biological processes (e.g., prefrontal functioning) affected by recurrent depression, as well as cognitive (i.e., rumination) and affective (e.g., emotion regulation) processes linked to the development of (recurrent) episodes of depression. Interestingly, although many affective disorders share similar neurobiological and cognitive features related to general emotion regulation, depression is characterized by a specific attentional bias at later stages of information processing, which fits with depression-specific biological (e.g., anterior cingu- 
late cortex hypoactivation) and cognitive (e.g., rumination) markers of vulnerability.

This review builds on the extant knowledge of cognitive and biological factors to explain how attentional processes provide a link between cognitive processes and biological factors. We will start from a cognitive perspective on depression vulnerability, followed by a review of the existing behavioral data on mood-congruent attentional bias in depression. Thereafter, we will situate these attention processes within a neurobiological view on increasing vulnerability to depression, providing an outline of the different building blocks of our framework. Finally, we will summarize the basic ideas in one framework. Although several of the cognitive and biological markers we will address have already been described separately in other reviews, our aim is to integrate these findings to understand the mechanisms underlying the kindling effect. We will outline cognitive and neurobiological evidence showing the mechanism of increasing vulnerability to the development of new depressive episodes.

\section{Cognitive Framework on Increasing Vulnerability to Depression}

Research on information processing in emotional disorders has predominantly been guided by the cognitive schema theory proposed by Beck (1967; Clark, Beck, \& Alford, 1999) and Bower's (1981) associative network theory. Beck and colleagues argued that information processing is guided by schemas, defined as memory structures that, on the basis of previous experiences, contain and organize information about the self, the world, and the future. Depression would be characterized by negative schemas involving loss and failure. These schemas are thought to bias encoding of information. Specific information-processing biases at the level of attention, interpretation, and memory mediate incoming information processing and subjective (emotional) experience. A fundamental aspect of Beck's cognitive model of depression is that cognitive structures or schemas remain latent until activated by relevant stimuli.

Although this model is very broad and general, the concept of cognitive reactivity is crucial to our understanding of how the cognitive model links to increasing vulnerability. Cognitive reactivity relates to fluctuations in negative self-attitudes in response to daily (stressful) events (Butler, Hokanson, \& Flynn, 1994). The crucial question is why certain individuals are or become more reactive to stressors than do others. The reason people become more sensitive to stressors after each depressive episode relates directly to our question of increasing vulnerability or to the "scar" hypothesis. Teasdale (1988) proposed the differential activation hypothesis (DAH) to account for this phenomenon. This framework assumes that depression becomes ever more severe or persistent because negative thinking patterns become more readily accessible and reactive on stressors and negative mood after each successive depressive episode. More specifically, the DAH assumes that during each episode the association between depressed mood and negative thinking patterns is strengthened. Therefore, a depressive mood, which can be evoked by daily stressors, reactivates the negative thinking patterns more easily with increasing depressive episodes. This associative network account can elegantly explain why, after multiple episodes, minor daily hassles leading to minor mood changes can result in a downward spiral of negative thinking patterns.

Many studies found supportive evidence for core predictions from the DAH. It has been shown that people who have experienced depression in the past-compared with never-depressed controls-report more dysfunctional attitudes, negative cognitive biases, and decreased positive biases after negative mood priming such as sad music, imaging of sad autobiographical memories, social rejection, sad film clips, or induced failure experiences (for a review, see Scher, Ingram, \& Segal, 2005). Importantly, longitudinal studies have shown that the existence of cognitive reactivity before a stressful life event predicts the onset of depressive episodes (e.g., Hankin, Abramson, Miller, \& Haeffel, 2004). For instance, a study by Segal, Gemar, and Williams (1999) investigated whether cognitive reactivity could predict relapse in a group of formerly depressed patients. Patients underwent negative mood induction, in which changes in dysfunctional attitudes were examined during both euthimic and induced transient dysphoric moods. The analyses showed that the magnitude of mood-induced cognitive reactivity significantly predicted relapse over a 4-year interval, with $70 \%$ of participants correctly classified as either relapsers or nonrelapsers. Such findings are indicative of a latent cognitive vulnerability for depression. In a recent study, it could be demonstrated that negative cognitions mediated the relationship between the number of past depressive episodes and poorer treatment response, which is in line with the idea that the threshold to react with negative cognitions decreases with accumulating episodes (Beevers, Wells, \& Miller, 2007). These data, in combination with the observation that the probability of relapse or recurrence increases 16\% with each episode (Solomon et al., 2000), are in line with the DAH conceptualization of increasing cognitive vulnerability.

However, an increased reactivity to sad moods after depressive episodes does not explain why vulnerable people are unable to stop negative thinking patterns and end up in enduring elaborative thinking patterns. Sheppard and Teasdale (2000) proposed two sources of dysfunctional thoughts in depression: (1) increased access to dysfunctional schemas, which refers to the process of schema activation, and (2) decreased monitoring of the thoughts and feelings that are the products of this schema activation, which they refer to as reduced metacognitive monitoring. They found evidence that depressed patients, compared with healthy controls, show both increased schema accessibility and decreased metacognitive monitoring. Importantly, remission is accompanied by improved metacognitive abilities, but the accessibility of schemas remains heightened compared with never-depressed controls (Sheppard \& Teasdale, 2004). This suggests that remission is mainly characterized by an increased ability to control negative thoughts, a mechanism that we will discuss in detail. 
Related to cognitive strategies in response to negative thoughts and mood, the response styles theory of depression, proposed by Nolen-Hoeksema (1991), states that the course of depression is strongly influenced by how one responds to depressive symptoms. People who respond to a sad mood and to depressive symptoms by engaging in uncontrollable ruminative thinking about the causes and consequences of their depression are more likely to remain longer in a depressed episode (Nolen-Hoeksema, Morrow, \& Fredrickson, 1993). Importantly, prospective studies have shown that rumination plays a role in both the onset and maintenance of depression (Nolen-Hoeksema, 2000). Cognitive reactivity and uncontrollable rumination are both of importance in increasing vulnerability for depression. A recent questionnaire study (Moulds et al., 2008) found evidence of a relationship between cognitive reactivity and a ruminative response style (response style questionnaire: Nolen-Hoeksema, 1991). This correlation between cognitive reactivity and rumination was significant even after controlling for current depressive symptoms. The latter finding warrants further consideration of the underlying mechanisms relevant to both processes.

In summary, mild dysphoria after a stressor can lead to the activation of negative schemas and continued elaboration on a negative mood, but this process does not explain why depression-prone individuals are unable to stop ruminative processes. We propose that diminished attentional control plays a crucial role in sustained negative cognitions and affect, linking cognitive and neurobiological evidence. We will describe a neurobiological account of attentional processes to gain a deeper understanding of these continued elaborative processes. In this account, we will emphasize the role of attentional processing of mood-congruent information. We start by considering the available data on dysfunctional attentional processes in depression.

\section{Attentional Characteristics of Depression}

Difficulty concentrating, which has been related to reduced attentional control (Ellis \& Ashbrook, 1988; Hertel \& Rude, 1991), is considered to be a characteristic symptom of depressive episodes (American Psychiatric Association, 2000). However, studies examining attentional functioning in general, using cognitive neuropsychological tasks, do not unambiguously support this idea. For instance, studies examining working memory tasks that heavily rely on attentional control have frequently failed to show strong and broad impairments in depressed versus nondepressed individuals (for a review, see Joormann, Yoon, \& Zetsche, 2007). Instead, studies indicate that depression is mainly characterized by attentional problems under conditions of set switching and/or dual-task conditions (Murphy et al., 1999; Rokke, Arnell, Koch, \& Andrews, 2002). The absence of broad impairments in the processing of neutral information has led investigators to start examining whether attentional impairments are observed under conditions of processing emotion-relevant, mood-congruent information.

Related to the prediction of schema-congruent information processing bias (Clark et al., 1999), a wealth of studies have examined whether attentional problems are observed when mood-congruent negative information is processed. This phenomenon is typically referred to as attentional bias, whereby depressed individuals, compared with nondepressed controls, show greater attention toward negative material than toward neutral material. Initial research failed to show clear evidence of attentional bias (for a review, see Mogg \& Bradley, 2005). Williams et al. (1997), in their influential theory on information-processing bias in anxiety and depression, even concluded that depression is not associated with mood-congruent attentional bias but is instead related to strategic elaboration of negative material, which causes improved explicit memory for this type of information. However, in recent neuropsychological and behavioral studies, it has consistently been found that, under specific conditions, attentional bias can be demonstrated (see below). These conditions include a relatively long stimulus presentation $(>1,000 \mathrm{msec})$ and self-relevant stimulus material (e.g., depression-relevant words, or emotional facial expressions). In addition, there are indications from behavioral high-risk studies (Beevers $\&$ Carver, 2003) and treatment studies (Teasdale, Segal, \& Williams, 1995) that attentional factors may play an important role in the etiology and maintenance of depression. Yet, to date, little is known about the conceptual nature of mood-congruent attentional bias in depression and its relation to other processing biases and biological factors in depression. In order to understand the influences of mood-congruent attentional bias on depressive symptomatology, an improved conceptualization of attentional influences on depression is required.

In addressing these issues, we will start by reviewing the empirical data on the association between depression and mood-congruent attentional bias. Most studies have been performed using behavioral tasks and eye-movement registration methodology. We have limited the review of empirical data to tasks that have been used frequently in the study of attentional bias in depression. Note that the data from the emotional Stroop task are not considered in this review. A concise review of these data has been provided by Williams, Mathews, and MacLeod (1996). Moreover, to date, the emotional Stroop task is not considered a valid measure of visual attention because of interpretational difficulties; in it, delayed color-naming of emotional words compared with neutral words has traditionally been taken as evidence for facilitated attentional capture by the emotional meaning of the words. However, it has been argued that delayed responding in this task cannot be unambiguously interpreted as an attentional effect. Alternative causes of delayed responding on emotional stimuli are, among others, general interference effects (Algom, Chajut, \& Lev, 2004) and cognitive avoidance (De Ruiter \& Brosschot, 1994).

This review draws on findings in clinically depressed individuals as well as in subclinically depressed individuals (referred to as $d y$ sphoric). These are individuals, often undergraduates, who indicate subclinical symptoms of depression on depression inventories. Although dysphoric individuals are not fully comparable with depressed individuals (see Ingram \& Siegle, 2009), many studies have 
been conducted with dysphoric individuals, and the inclusion of these data provides a richer database for the present purposes. We included only studies in which a clear distinction can be made between dysphoric and nondysphoric individuals (excluding correlations and mediansplit procedures without any preselection). A comprehensive overview of all separate studies (from 1986 to 2008) is provided in the Appendix. In the text, we briefly describe the procedure of each task, describe the commonly observed pattern of data, and highlight some of the most relevant findings.

\section{Empirical Data on Mood-Congruent Attentional Bias in Depression}

Visual dot probe task. In response to the interpretational problems of the emotional Stroop task, the dot probe paradigm was developed by MacLeod, Mathews, and Tata (1986) to examine selective visual attention. In their initial study, word pairs (one emotional, one neutral) were presented at two spatially separated locations (one upper, one lower location) of a screen, followed by a dot probe. The main assumption of this task is that individuals will respond faster to probes presented at the spatial location that is previously attended, typically in function of selective attention toward emotional rather than neutral information. Careful inspection of data generated by dot probe studies reveals an interesting pattern of results. There is no evidence for attentional bias at presentation durations of less than $1 \mathrm{sec}$. However, when a presentation duration of $1 \mathrm{sec}$ or longer was used, six out of seven studies provided some evidence for an attentional bias for negative information, although there is considerable variation in the precise nature of these effects across the studies. This effect is observed in clinically depressed individuals (e.g., Gotlib, Kasch, et al., 2004; Gotlib, Krasnoperova, Yue, \& Joormann, 2004; Joormann \& Gotlib, 2007), as well as dysphoric individuals (Bradley, Mogg, \& Lee, 1997; Shane \& Peterson, 2007).

There is also some evidence of absence of positive bias in depression and dysphoria. In depressed or dysphoric individuals, there is usually no bias toward positive material, whereas nondepressed individuals frequently orient more strongly toward positive than toward neutral information. However, reduced attention toward positive material in the dot probe task is found only in some studies, and is not unambiguously supported across studies.

Deployment of attention task. This task was developed by Gotlib, McLachlan, and Katz (1988). It bears a number of similarities to the dot probe task, but is based on a different rationale. In this task, word pairs are presented on two vertically separated locations. Two differently colored bars subsequently replace these words. Participants are misinformed that one of the colored bars will temporally precede the other bar and are required to determine which bar was presented first. Based on the idea that bars presented at attended locations will be detected more rapidly (cf. the law of prior entry; Titchener, 1908), this paradigm allows investigating whether attention is systematically drawn to certain classes of information.
In contrast to the dot probe task, only a couple of studies have been performed using this methodology, and it has generated consistent but surprising data. This set of studies found that depressed individuals are characterized by a lack of (1) the attentional bias for positive words present in nondepressed individuals (positive bias; Gotlib et al., 1988 ); or (2) the attentional avoidance of negative information present in nondepressed individuals (protective bias; McCabe \& Gotlib, 1995). The absence of attentional bias has been related to the concept of "even-handedness" by depressed individuals, referring to an absence of attentional preferences for either positive or negative material due to their amotivational state. These findings in clinically depressed individuals have also been replicated in dysphoric individuals.

Clearly, data from the deployment-of-attention task differ from the findings in the dot probe task. It must be noted that this task has been used less frequently than has the dot probe task, so there is little information on the precise attentional processes and experimental parameters in it. Moreover, this task has been used only with emotional words instead of with more potent stimulus material, such as emotional facial expressions.

Visual search task. The visual search task is a wellestablished paradigm in experimental psychology. It investigates the automatic versus the controlled detection of stimuli (Treisman \& Souther, 1985). In a typical version of this task, individuals are asked to indicate the presence of a target stimulus within an array of distracting stimuli. Hansen and Hansen (1988) were the first to develop an emotional face-in-the-crowd variant of this task. Recently, this task has also been used to examine attentional bias for emotional material in depression.

In a first study (Suslow, Junghanns, \& Arolt, 2001), individuals had to examine displays of schematic faces in the presence of a negative or positive target stimulus. These displays were presented for a relatively short duration, and the data showed that depressed individuals were slower to detect the positive faces. In a second study (Suslow et al., 2004), the same effect was found in a depressed population in remission. It is important to note that the two studies by Suslow and colleagues were specifically aimed at the initial detection of emotional information in depression.

Using a different approach, Rinck and Becker (2005) had individuals search for four categories of target words embedded in four categories of distracting words. In this task, either neutral or valenced targets were presented within an array of either neutral or valenced distractors. With this approach, a differentiation could be made between detection and distraction of certain classes of valenced information. The outcome of that study was that depression was associated with increased distraction by negative words. However, these findings were not replicated by a recent study presenting schematic faces (Karparova, Kersting, \& Suslow, 2007). One important issue in explaining this mixed pattern of findings is that, in the visual search paradigm, participants tend to base their search strategy on lower level visual features instead of the emotional meaning of stimuli (see Cave \& Batty, 2006). Search strategies based on lower level features may 
reduce the amount of attention to more holistic, emotionally relevant material.

Exogenous cuing paradigm. Posner's (1980) exogenous cuing paradigm is a commonly used task in cognitive experimental psychology, and has been used to distinguish between specific attentional operations. The emotional modification of this spatial cuing task allows the investigation of two attentional operations: (1) attentional engagement with a new stimulus, and (2) attentional disengagement from a previously attended stimulus. Recently, it has been argued that the assessment of these two different components is important in determining the nature of attentional bias (Fox, Russo, Bowles, \& Dutton, 2001; Koster, De Raedt, Goeleven, Franck, \& Crombez, 2005). In fact, Bradley, Mogg, and Lee (1997) already suggested that this distinction might map onto the differentiation between processing biases at initial versus later stages of information processing, with depression being more strongly associated with the bias at later stages.

In this task, participants are asked to detect a visual target presented on the left or right side of a fixation cross. On a proportion of the trials ("valid" trials), a peripheral cue precedes the target at the same spatial location. On the remaining trials ("invalid" trials), the target is presented at the opposite spatial location from the cue. In the emotional modification of this paradigm, the emotional value of the cue is systematically varied (e.g., negative/neutral). This allows the investigation of attentional engagement by emotional cues through examination of reaction time (RT), and/or accuracy, benefits on valid trials cued by emotional versus neutral information. Attentional disengagement from emotional cues can be studied through examination of RT costs on invalid trials cued by emotional versus neutral information.

At short intervals between cue onset and target onset (stimulus onset asynchrony [SOA] $<300 \mathrm{msec}$ ), participants are typically faster to respond to the valid than to the invalid trials. This is called the cue validity effect. At longer SOAs, the cue validity effect disappears and even reverses, because attention to the location of a previously attended stimulus is inhibited in favor of new locations. This is the inhibition of return effect (IOR; Posner \& Cohen, 1984). Two strategies have been applied to investigate attentional bias in psychopathology in this paradigm. First, with short SOAs between cue and target, attentional engagement and disengagement have been investigated. Second, with longer cue presentations or SOAs, one can examine the emotional modification of the IOR as well. It may be expected that, in the case of emotionally relevant stimulus material, the IOR will not emerge as easily as with neutral information, because of impaired attentional disengagement. This would mean that the time course of the cue validity effect was extended with emotional stimuli (hereafter referred to as "the enhanced cue validity effect"). Using the spatial cuing task, Derryberry and Reed (2002) showed that the temporal processing of negative information in high-traitanxious individuals was modulated by their level of attentional control. At later stages of information processing, anxious individuals who score high on attentional control avert attention from negative information, whereas those with low attentional control still show an attentional bias for such information.

The emotional modification of a cuing task was applied in a study on attention for negative and positive words in dysphoric and nondysphoric individuals (Koster et al., 2005). In two experiments using long cue presentations, it was observed that dysphoric individuals showed a greater cue validity effect for negative words than did nondysphoric individuals. This effect was positively correlated with impaired disengagement from negative material in the dysphoric individuals. These effects were replicated in a clinically depressed sample using emotional facial expressions as cues (Leyman, De Raedt, Schacht, \& Koster, 2007). In addition, the dysphoric individuals oriented less to positive words than did the nondysphoric individuals. In a study with dysphoric and nondysphoric participants (Ellenbogen, Schwartzman, Stewart, \& Walker, 2002), it was found that, under stress, dysphoric individuals had difficulty disengaging from cues. However, this effect occurred regardless of cue valence (Ellenbogen et al., 2002). In sum, spatial cuing studies have been successful in isolating the components of attentional bias in depression, suggesting that attentional disengagement of negative information is impaired.

Eye-movement methodology. One important problem of the aforementioned tasks is that attention is investigated in conditions under which individuals are performing a primary task, and emotional material is presented as distracting, task-irrelevant information. Arguably, it could be that these specific task conditions lead to an underestimation of attentional bias, since emotional information is often task relevant and important to the individual's goal. Moreover, it is noteworthy that the behavioral paradigms discussed all depend on RT data, with depression being associated with response slowing that may hamper the interpretation of such data.

Therefore, researchers have argued that eye-movement recording allows a more valid measure of attention in depression. In studies using eye registration, various methodologies have been applied to examine attentional bias. A first study by Matthews and Antes (1992) examined eye fixations to sad, happy, and neutral regions of pictures, mean gaze time for each of these regions, and mean number of first fixations. Dysphorics and nondysphorics both fixated more and longer on happy material than on sad material. However, the dysphorics did fixate more on the sad regions than did the nondysphorics. In a study by Mogg, Millar, and Bradley (2000), initial orienting biases were examined by combining a dot probe task with eyeregistration methodology. They specifically examined direction and latency of the first eye movement in response to emotional faces. This study revealed no differential attentional effects for emotional faces in the depressed individuals compared with the controls. Given the findings presented earlier, it is not surprising that depressed individuals did not display initial attentional bias.

In a naturalistic viewing study, fixation time (total time looked at a picture), fixation frequency (number of fixations), and glance duration (average duration of fixation for emotional versus neutral photographs) were examined 
in depressed individuals (Eizenman et al., 2003). Using these indices, it was found that depressed individuals had a longer fixation time and longer glance duration for dysphoric pictures than did controls. These data are similar to the findings in the dot probe and the spatial cuing task. Recent studies in which individuals were viewing emotional information provide further evidence of the impaired disengagement hypothesis (Caseras, Garner, Bradley, \& Mogg, 2007; Kellough, Beevers, Ellis, \& Wells, 2008; Leyman, De Raedt, Vaeyens, \& Phillipaerts, in press).

Summary. Despite initial mixed findings on attentional bias, there is now converging evidence from dot probe, spatial cuing, and eye-registration studies that depression is associated with impaired attentional disengagement. This effect is mainly found when longer stimulus presentations are used, which is indicative of a bias at later stages of processing. Moreover, this bias reveals itself to be specific to negative self-relevant material, although the absence of a positivity bias observed in nondepressed people has also been observed. It is noteworthy that, although the corpus of empirical data on attention in depression mainly relies on visuospatial tasks, the finding of impaired disengagement from negative material has also been corroborated in a recent study using a modified attentional blink task that did not rely on spatial attention processes (Koster, De Raedt, Tibboel, De Jong, \& Verschuere, 2009).

\section{Attentional Bias, Attentional Control, and Depression Vulnerability}

Although many researchers start from the assumption that attentional bias is a vulnerability factor for the development of depression, the studies mentioned above are all cross-sectional, which means that it is impossible to make inferences about causality. In this section, we will discuss prospective and experimental studies investigating the causal relationship between attentional bias, emotional reactivity, and depressive symptoms. Thereafter, we will explore the link between attentional bias and depression-relevant cognitive processes related to emotion regulation.

Causal influence of attentional bias on depression. In cognitive theories, information processing biases are considered to be a vulnerabiliy factor for the etiology, maintenance, and recurrence of depressive episodes (Clark et al., 1999). However, assumptions on a causal relationship between attentional biases and depression can only be confirmed by research that goes beyond crosssectional designs. A number of prospective studies suggest that attentional bias is associated with emotional reactivity and precedes the development of anxiety and depression. In a seminal study by MacLeod and Hagan (1992), an emotional Stroop task was administered to a group of women before they underwent a gynecological examination. Although, as mentioned before, Stroop effects cannot unequivocally be considered a valid index of attentional bias, the results of this study are interesting. It was found that a bias toward subliminally presented negative information was the best predictor of enhanced emotional reactivity to a stressful outcome. In the context of depression, Beevers and Carver (2003) demonstrated that attentional biases, as measured with a dot probe task, interacted with intervening life stress to predict higher scores on depression 7 weeks later. Furthermore, another study using a dot probe task has demonstrated a moodcongruent attentional biases after a negative mood induction in never-depressed offspring at risk for the development of depression (Joormann, Talbot, \& Gotlib, 2007).

Importantly, no strict conclusions concerning causal hypotheses can be drawn from prospective studies, because the influence of a potential third factor that could account for the established associations cannot be ruled out. It could be that participants demonstrating an attentional bias at pretesting differed from the individuals who did not demonstrate an attentional bias on variables not controlled for. The only way to adequately address causal hypotheses is by experimentally manipulating attentional bias in order to test whether variations in the bias influence the emotional reactivity or depressive symptoms.

To experimentally manipulate attentional bias, cognitive bias modification (CBM) procedures have been developed (MacLeod, Koster, \& Fox, 2009). These procedures intend to train the participant in orienting toward or away from specific emotional stimuli through systematic manipulation of contingencies between the valence of the stimulus and the location of a target to which the participant has to respond. Using a modified dot probe task, MacLeod, Rutherford, Campbell, Ebsworthy, and Holker (2002) created a task in which the dot probe appeared at the same location of the negative cue in every trial to induce attentional bias. This prompted the participant to orient toward the negative information. To reduce attentional bias, the dot probe was set to always appear on the opposite side of a negative stimulus, prompting participants to divert their attention from negative information.

Several studies investigating this type of attentional training procedure have been able to successfully modify attentional bias, and they found significant effects on emotional reactivity to induced or to real-life stressors in normal volunteers (e.g., Dandeneau \& Baldwin, 2004; Dandeneau, Baldwin, Baccus, Sakellaropoulo, \& Pruessner, 2007; MacLeod et al., 2002). These results confirm the hypothesized causal relationship between attentional bias and vulnerability factors associated with the development of emotional disorders. Moreover, a recent study investigated attentional retraining in dysphoria (Wells \& Beevers, in press). During a period of 2 weeks, 16 dysphoric students completed four sessions of attentional training. The participants in the training condition reported significantly fewer depressive symptoms immediately after training (effect size: $d=0.52$ ), as well as at a follow-up 2 weeks later (effect size: $d=1.04$ ), than in a no-training condition. Interestingly, improvement in the training condition was mediated by change in attentional bias. These preliminary results are in need of replication, but they are in line with the assumption of causality ascribed to biased attention in the course of depressive symptoms.

Influence of attentional bias on cognitive processes. Depression is generally considered to be associated with a wide range of affective and somatic symptoms, as well as 
with cognitive deficits. One could argue that attentional bias will have a proximal relationship to cognitive processes implicated in depression. In emerging research, attentional bias has been investigated in relation to rumination and memory.

As we discussed earlier, a ruminative thinking style is considered an important cognitive risk factor in depression, as shown by prospective studies (e.g., Nolen-Hoeksema, 2000). Attentional bias may contribute to the continuous elaborated processing of negative information observed in depressed individuals. In fact, rumination has sometimes even been defined in relation to attention, with, for instance, Nolen-Hoeksema et al. (1993) stating that ruminative responses are "behaviors or thoughts that focus an individual's attention on his or her depressed mood, and [on] the possible causes and consequences of that mood" (p. 20). This relation has been confirmed in a dot probe study in depressed patients, in which trait rumination was associated with an attentional bias toward negative words even when depressive symptoms were statistically controlled for (Donaldson, Lam, \& Mathews, 2007). This also provides crucial confirmation that data from behavioral measures of attention can be related to internal attentional processes.

Attention is also considered to be related to inhibitory control and working memory; that is, it plays a role in preventing irrelevant emotional material from entering working memory, and it is important in the updating of working memory, with both concepts being crucial in emotion regulation (see Joormann \& Gotlib, 2008). To our knowledge, there is no empirical research directly linking the concepts of impaired disengagement, inhibition, and working memory in depression. Nevertheless, it is worth mentioning that depression was found to be associated with impaired inhibition of negative material (Goeleven, De Raedt, Baert, \& Koster, 2006; Joormann, 2004) and impaired abilities to remove negative material from working memory (Joormann \& Gotlib, 2008).

Finally, there is also some research linking attention and memory bias in depression. Depression has been robustly related to biased recall of information on explicit memory tests, with greater recall of negative information than of neutral and positive material, whereas healthy controls show greater memory for positive material than for negative and neutral material (e.g., Bradley, Mogg, \& Williams, 1995; Denny \& Hunt, 1992). In a first study, it has been found in clinically depressed individuals that incidental recall of emotional words did not correlate with attentional bias (Gotlib, Kasch, et al., 2004). However, in that study, stimuli from the attentional tasks (pictures) were different from those in the recall task (words), reducing the probability of finding strong correlations. In a recent study, an incidental free-recall test was administered immediately after a spatial cuing task, examining recall of the words (negative, positive, and neutral words) presented during the attention task. In dysphoric individuals, it was found that attentional bias toward negative words was associated with enhanced recall of these negative words relative to neutral words. This effect remained significant even when depression severity was controlled for (Koster, De Raedt, Leyman, \& De Lissnyder, 2010).
Summary. In the preceding sections, we have discussed research indicating that attentional bias toward negative information may be causally related to emotional reactivity and depressive symptoms. Moreover, there is emerging research linking attentional bias with other depression-relevant cognitive processes and products, such as rumination and memory. In addition, there are interesting links between attentional bias, attentional inhibition, and working memory, all processes heavily involved in emotion regulation.

In the next section, the attention deficiencies observed in depression will be framed within a neurobiological account, starting from stressors in the environment that activate the hypothalamic pituitary adrenocortical (HPA) axis with a specific influence on the serotonin metabolism, leading to decreased activity in prefrontal areas. This decreased activity in prefrontal areas is associated with attenuated inhibition of subcortical regions, resulting in prolonged activation of the amygdala and an impaired ability to exert attentional inhibitory control over negative elaborative processes such as rumination. These elaborative processes are caused by the activation of negative schemas after confrontation with stressors. Impaired attentional control can explain the cascade of depressive symptoms in relation to enhanced elaboration of negative information: problems in emotion regulation and persistent negative affect.

\section{Neurobiological Underpinnings of Impaired Attentional Control and Depression Vulnerability}

The HPA axis. Many studies show that stressors induce biological changes over time, at both hormonal and neurochemical levels (Thase, 2009). The HPA axis is the hallmark of the stress response, stimulating the release of corticosteroids. The HPA axis is stimulated in reaction to the perception of stressors, which takes place in different subcortical areas, depending on the nature of the stressor. Subcorticol areas immediately activated following stress exposure are located in the limbic system, such as the thalamus, amygdala, and hippocampus (Sergerie, Chochol, \& Armony, 2008).

Neuronal input from these and other related brain regions reaches the hypothalamus, and this activating input provokes the release of adrenocorticotrophic hormonereleasing factor (CRF), which in turn activates the secretion of adrenocorticotrophic hormone (ACTH) in the pituitary. ACTH travels via the bloodstream to the adrenal cortex in the periphery of the body, where it targets receptors in the adrenal cortex to release glucocorticoid hormones (cortisol). An important aspect of the HPA system is the inhibitory feedback regulation after the stressor has disappeared, inhibiting CRF in the hypothalamus as well as the secretion of ACTH in the pituitary. This feedback mechanism is regulated by the glucocorticoids interacting with their receptors in multiple target tissues related to the HPA axis (Pariante \& Lightman, 2008).

The activated HPA axis regulates bodily functions such as glucose and lipid metabolism and immunity, which promotes survival in life-threatening situations. Moreover, the HPA axis also has important effects on the brain. For 
example, glucocorticoids regulate neuronal survival and neurogenesis, influence the size of the hippocampus, and are related to the acquisition of new memories and emotional appraisal processes (Herbert et al., 2006). However, sustained cortisol hyperdrive over time has detrimental effects because it increases the risk for hypertension, obesity, heart disease, and several autoimmune diseases (McEwen, 2000).

Many studies over the last decades have demonstrated that hyperactivity of the HPA axis is one of the most consistent biological findings in depression (van Praag, de Kloet, \& van Os, 2004). Sustained hypercortisolism can result from dysfunctional glucocorticoid-mediated feedback inhibition (Holsboer, 1995) and there is accumulating evidence that prolonged hypercortisolism can impair the HPA axis permanently (Sapolsky, 1996). By demonstrating that the HPA axis is not suppressed by pharmacological stimulation with an oral dose of the synthetic glucocorticoid dexamethasone (the dexamethasone suppression test) (Holsboer, 1995), many studies show that feedback inhibition is impaired in major depression. Melancholic depression can be conceptualized as a prolonged and intensified stress response of the HPA axis, which results in a disruption of the homeostatic interplay between prefrontal cortex and amygdala activity (Gold \& Chrousos, 2002).

HPA axis dysfunctioning remains a cornerstone of neurobiological depression research, despite open questions on the specificity for depression and the melancholic subtype of depression (van Praag et al., 2004). In a recent review, Pariante and Lightman (2008) concentrated on the most recent advances in this research area. They present data supporting the hypothesis that HPA axis hyperactivity is not a consequence or an epiphenomenon of depression but is a risk factor predisposing to the development of depression, influenced by early stressful life experiences programming molecular changes, as well as by genetic liability. In an exemplary study, women who have been sexually or physically abused in childhood, even if they are not currently depressed, show enhanced ACTH and heart rate responses when exposed to a standardized psychosocial stressor. Moreover, during a depressed episode, they show the largest increase in ACTH secretion and heart rate, as well as a large increase in cortisol secretion (Heim $\&$ Nemeroff, 2001). In clinical studies, indications have been found that normalization of HPA axis functioning following treatment with antidepressive drugs might be a prerequisite for stable remission of depression, showing that persistent cortisol nonsuppression in the DST after recovery is predictive for relapse (e.g., O'Toole, Sekula, \& Rubin, 1997). Such findings indicate that dysregulation of the HPA system is associated with relapse and persistency of depression (Mizoguchi, Shoji, Ikeda, Tanaka, \& Tabira, 2008). Importantly, it has been demonstrated that recovered depressed patients continue to show a disturbed HPA axis functioning (Bhagwagar, Hafizi, \& Cowen, 2003), which means that it is not only an epiphenomenon of a depressed state.

The relationship between the HPA axis and neurotransmitter systems. A large number of studies show a relationship between HPA axis functioning and monoaminergic neurotransmission, more specifically the serotonin metabolism. For example, research by Mizoguchi and coworkers illustrates this interaction in animal studies. In line with many other studies, chronically stressed rats show a dysregulation of the HPA system, characterized by dexamethasone negative feedback resistance (Mizoguchi et al., 2001). Moreover, chronic stress also reduces serotonergic transmission in the PFC (Mizoguchi, Yuzurihara, Ishige, Sasaki, \& Tabira, 2002), and there are indications that serotonin $\left(5-\mathrm{HT}_{1 \mathrm{~A}}\right)$ receptors are downregulated as a consequence of chronic stress exposure (López, Liberzon, Vázquez, Young, \& Watson, 1999). Importantly, it has been demonstrated that there are reciprocal causal interactions between the HPA axis and the 5-HT system (Lanfumey, Mongeau, Cohen-Salmon, \& Hamon, 2008).

In line with these results and HPA axis studies, it has been demonstrated that the serotonin (5-hydroxytryptamine or 5-HT) system is influenced by animal maternal deprivation (Gardner, Thrivikraman, Lightman, Plotsky, \& Lowry, 2005). Importantly, the HPA axis is also under tonic 5-HT (inhibitory) neurotransmission (see previous paragraph on the feedback mechanism). Clinical improvement after antidepressant treatment with selective serotonin reuptake inhibitors (SSRIs), which temporarily normalizes 5-HT functioning, has been associated with a normalization of HPA system function, and other antidepressants may act in the same way in attenuating the HPA axis (Barden, 2004; Keck \& Holsboer, 2001). However, it has also been shown that recovered depressed patients continue to show overall decreased 5- $\mathrm{HT}_{1 \mathrm{~A}}$ receptor availability (Bhagwagar, Rabiner, Sargent, Grasby, \& Cowen, 2004), which means that disruption in the serotonin metabolisms may be a scar of past depressive episodes, increasing vulnerability for future episodes. Of course, it remains an intriguing question whether this diminished receptor availability might also be related to the use of SSRIs.

One of the most important research findings over the last decade is that genetic polymorphisms in serotoninrelated genes can modify susceptibility to developing depression following stressful life events (for a review, see Uher \& McGuffin, 2008). This has first been shown for the genes encoding the 5-HT transporter, affecting the reuptake of serotonin back into the presynaptic cell, where a gene by environment interaction was clearly observed (Caspi et al., 2003). That is, individuals with a specific 5-HT transporter gene promoter region (5-HTTLPR) polymorphism (allelic variation in this region: $\mathrm{S} / \mathrm{S}$ genotype) were more likely to develop depressive symptoms after stressful life events. Although a recent meta-analysis (Risch et al., 2009) failed to replicate the original Caspi et al. study, the 5-HTTLPR polymorphism has been linked to biological as well as to cognitive factors involved in stress reactivity; for example, a study by Gotlib, Joormann, Minor, and Hallmayer (2008) found that adolescent girls with the specific 5-HTTLPR polymorphism showed an increased cortisol response to experimentally induced stress. Recently, a variant of the L-form for the serotonin transporter has also been found to be associated with melancholic depression (Firk \& Markus, 2007). Other genes 
involved in serotonergic neurotransmission relevant for depression include, among others, tryptophan hydroxylase (TPH1 and TPH2, enzymes related to serotonin synthesis) and the genes encoding the $5-\mathrm{HT}_{2 \mathrm{~A}}$ receptor $(5 \mathrm{HTR} 2 \mathrm{~A}$; Levinson, 2009).

The observation that some polymorphisms can modify susceptibility to developing depression upon stressors may suggest that the mutual relationship between HPA axis functioning and the serotonin metabolism is also dependent on genetic vulnerability factors (Firk \& Markus, 2007).

The 5-HT neurotransmitter system and its relationship with prefrontal cortex and attention. Serotonin is mainly synthesized in the midbrain raphé nuclei. These 5-HT neurons project to virtually all brain regions, cortical as well as subcortical areas (Kingsley, 2000). Although there are \pm 15 different types of serotonin receptors, two specific receptors, $5-\mathrm{HT}_{1 \mathrm{~A}}$ and $5-\mathrm{HT}_{2 \mathrm{~A}}$, are mainly important for the pathophysiology of depression and are targeted by antidepressant medication (SSRIs; Mann, Brent, \& Arango, 2001).

Serotonin plays an important role in cognition and emotion, with implications for affective disorders such as depression and anxiety. Interestingly, the serotonin system is related to emotion regulation, most likely through its effects on attentional control over negative stimuli; that is, many experimental studies show that $5-\mathrm{HT}$ is implicated in enhanced sensitivity to negative stimuli and modulates the responsiveness of the amygdala via connected frontal regions (for reviews, see Cools, Roberts, \& Robbins, 2007; Hariri \& Holmes, 2006). Moreover, the amygdala response to negative stimuli is revealed to be associated with the above-mentioned polymorphism of 5-HT (e.g., Dannlowski et al., 2008). It has been proposed that the short allele variant, associated with a reduced 5-HT function, causes increased brain responses to negative stimuli (Bethea et al., 2004). Beevers, Wells, Ellis, and McGeary (2009) also demontrated that variations in the 5-HT polymorphism are associated with attentional processing of emotional information in a nonclinical population. It was found that short allele carriers show impaired disengagement from emotional material.

On the basis of an extensive literature review (Carver, Johnson, \& Joormann, 2008), it has been proposed that the relationship between low serotonergic function and decreased reduced inhibition of negative affective states can be linked to emotion-attention networks in the brain. One of the key structures in this network is the dorsolateral prefrontal cortex (DLPFC). It has been proposed that the DLPFC initiates emotion regulation, causing inhibition of the amygdala (Davidson, Pizzagalli, Nitschke, \& Putnam, 2002; Mayberg, 1997, 2002, 2003; Ochsner, Bunge, Gross, \& Gabrieli, 2002). The amygdala is the foremost brain region implicated in emotion processing, involved in detecting, generating, and maintaining emotions (Phan, Wager, Taylor, \& Liberzon, 2004). Depression has been conceptualized as a failure of dorsal areas, related to cognitive control, to regulate ventral emotion producing systems (Phillips, Drevets, Rauch, \& Lane, 2003), based on evidence of abnormalities in these pathways in depressed patients that change after treatment (Mayberg, 1997). Moreover, recent research shows that a functional balance between ventral and dorsal regions in the brain is important for maintaining homeostatic emotional control. A widely distributed and functionally interactive network of cortical-limbic pathways plays an important role in cognitive regulation of mood (Johnstone, Van Reekum, Urry, Kalin, \& Davidson, 2007; Ochsner \& Gross, 2008; Seminowicz et al., 2004). Emotion-arousing stimuli activate the amygdala (Zald, 2003), which is closely connected to the anterior cingulate cortex (ACC). The ACC integrates signals from the ventral $\mathrm{ACC}$ and the dorsal ACC (Bush, Luu, \& Posner, 2000), the former related to emotion processing (e.g., Yücel et al., 2003), the latter being implicated in the facilitation of task-appropriate response selection and conflict monitoring (MacDonald, Cohen, Stenger, \& Carter, 2000). The ACC signals to the DLPFC to alter the direction of attention or to modify the distribution of processing resources (Hopfinger, Buonocore, \& Mangun, 2000), which in turn sends feedback signals to the subcortical system in order to suppress emotion processing in the amygdala (Wager, Davidson, Hughes, Lindquist, \& Ochsner, 2008), via connections with other frontal regions such as the orbitofrontal cortex (OFC; Taylor \& Fragopanagos, 2005). Abnormalities in DLPFC and ACC activity have been commonly observed in depression, specifically during tasks related to emotion processing (Fales et al., 2008) and cognitive control (Holmes \& Pizzagalli, 2008). This reciprocal mechanism can elegantly explain the specific mood-congruent nature of attentional control problems in depression.

In relation to this emotion-processing network, emerging research has modeled the depressogenic effects of reduced frontal functioning related to the serotonin metabolism. In a recent study investigating postsynaptic $5-\mathrm{HT}_{2 \mathrm{~A}}$ receptor binding in a sample of severely depressed patients (Baeken et al., 2010), as measured with ${ }^{123}$ I-5-I-R91150 single photon emission computed tomography (SPECT) before and after 10 daily sessions of treatment with repetitive transcranial magnetic stimulation (rTMS: a technique to safely depolarize the underlying neurons of particular areas in the human brain cortex) of the left DLPFC, it was observed that, compared with a control group, patients displayed significantly less baseline $5-\mathrm{HT}_{2 \mathrm{~A}}$ receptor binding index (BI) in the frontal cortex, and the antidepressant effect of high-frequency rTMS (HF-rTMS) treatment correlated positively with $5-\mathrm{HT}_{2 \mathrm{~A}}$ receptor $\mathrm{BI}$ in the DLPFC. Moreover, it was found that one session of HF-rTMS over the right DLPFC in healthy volunteers, which is thought to induce a lateralized frontal brain activity pattern characteristic of depressed people (Davidson et al., 2002), produced instant impairments in the ability to inhibit negative information (Leyman, De Raedt, Vanderhasselt, \& Baeken, 2009). Moreover, in severely depressed treatment-resistant people, a 10-day treatment period with rTMS over the left DLPFC, which is thought to induce a lateralized frontal brain activity pattern characteristic of nondepressed people, was administered. Using this procedure, 9 out of 14 patients demonstrated significant mood improvements, as indexed by a reduc- 
tion of more than $50 \%$ on the Hamilton depression rating scale (Leyman, De Raedt, Vanderhasselt, \& Baeken, in press). Of particular relevance to the present purposes is the fact that, compared with nonresponders, responders demonstrated improvements in the inhibitory processing of negative information.

Although regions of the dorsal PFC are activated when people engage in reflective top-down processing, as in reappraising emotional stimuli in order to regulate emotional responses (e.g., Ochsner et al., 2002), or in effortful suppressing emotion on demand (e.g., Beauregard, Lévesque, \& Bourgouin, 2001), the studies mentioned above that use attention and inhibition tasks unrelated to effortful regulatory processing suggest that the DLPFC is also involved in a more automatic mode of attentional control.

Taken together, these observations suggest that the 5-HT metabolism could be related to attentional inhibition for negative stimuli in a specific circuitry of emotion regulation, in which the DLPFC cortex has an important role. Empirical evidence linking the 5-HT metabolism to dysregulated information processing and depression has also been obtained in studies using an elegant and well-studied procedure to temporarily decrease levels of serotonin experimentally, by artificially depleting people of L-tryptophan (dietary manipulation), a precursor to serotonin. Yatham et al. (2001) observed that tryptophan depletion decreased 5- $\mathrm{HT}_{2 \mathrm{~A}}$ receptor BI in the DLFPC, which indicates that receptors in this area are particularly sensitive to serotonergic variation. These results fully concur with the above-mentioned SPECT study of Baeken et al. (2010), which showed that increased $5-\mathrm{HT}_{2 \mathrm{~A}}$ receptor binding is related to the antidepressant effect of rTMS in depressed people. Importantly, in a recent study, tryptophan depletion also reduced the normal attentional bias toward positive stimuli in healthy people, which was accompanied by increased hemodynamic responses (fMRI) during the processing of emotional words in several subcortical structures (Roiser et al., 2008). In a review including 25 studies (Merens, Van der Does, \& Spinhoven, 2007), serotonin manipulations were found to affect facial emotion recognition, attentional bias, emotional memory, dysfunctional attitudes, and decision making. Taken together, these findings are also in line with the previously mentioned study showing a decreased attentional control for negative stimuli after rTMS of the DLPFC (Leyman et al., 2009). Interestingly, tryptophan depletion causes a temporary increase in depressive symptoms among formerly depressed persons (e.g., Booij \& Van der Does, 2007; but see Leyton et al., 1997). This effect is not observed in people who show no history of depressive episodes or other risk factors (Ruhé, Mason, \& Schene, 2007). Moreover, the finding that only people with the short variant of the 5-HTTLPR gene show depressive symptoms after tryptophan depletion is also indicative of a relation between genetic and neurochemical vulnerability for depression.

Finally, another way to investigate the relationship of 5-HT and emotional processing is to improve 5-HT function with SSRIs. Harmer and colleagues (Harmer, Mackay, Reid, Cowen, \& Goodwin, 2006; Harmer, Shelley, Cowen,
\& Goodwin, 2004) administered citalopram (20 mg/day) over 7 days, facilitating recall of positive information and impairing detection of facial expressions of anger and fear in healthy volunteers. Finally, a single intravenous dose of citalopram attenuated the increased sensitivity for fearful expressions of formerly depressed patients (Bhagwagar, Cowen, Goodwin, \& Harmer, 2004). All these data are consistent with the idea that the serotonin metabolism mediates attentional bias for emotional material in a specific neurocircuitry of attentional control.

\section{Summary: An Integrative Framework}

In the preceding sections, we have reviewed the empirical evidence that composes the building blocks of our framework. A basic outline of our framework is provided in Figure 1.

The framework can explain from a biological stance the kindling effect of an increased vulnerability to depression after each episode in genetically vulnerable people. Importantly, each of the building blocks of our framework shows characteristics that remain disturbed in recovered patients.

The HPA axis becomes increasingly impaired after periods of hypercortisolism during depressive episodes, which means that it becomes more reactive to stressors. This can lead to decreased activity in DLPFC areas, since activity in this structure is mediated by the serotonin metabolism, which is under control of an HPA axis. In our conceptualization, decreased activity in DLPFC areas is linked with prolonged activation of the amygdala in response to stressors in the environment. Impaired attenuation of amygdala activity through reduced frontal control leads to sustained negative affect. Decreased DLPFC activity also causes attentional impairment at the cognitive level, mediating sustained emotional responding to stress. We thus conceive the increasing vulnerability as an interaction between cognitive and biological factors in which the vulnerability relates to a dysfunctional reaction on stressors. We propose that the crucial link between cognitive and biological vulnerability is attentional control, because decreased inhibitory control and maintained attention for negative material leads to impaired ability to stop negative elaborative processes, such as rumination, and consequent sustained negative affect. The mood-congruent nature of attention impairment is related to the fact that emotional processing in the amygdala no longer causes increased cognitive control in the DLPFC, mediated by the ACC. Although this does not rule out the existence of general impaired cognitive control, maintained attention to negative information is, in contrast to anxiety, specifically related to depression. The ruminative process is caused by the activation of negative schemas. Because the association between depressed mood and negative thinking patterns is strengthened after each episode, negative thinking patterns become more reactive to negative moods and stressors, with increasing depressive episodes. Moreover, the elaborative process can act as an internal stressor, activating the stress system. The relationship between our biological and cognitive conceptualization is compatible with the finding that people who have a tendency to ruminate show, 


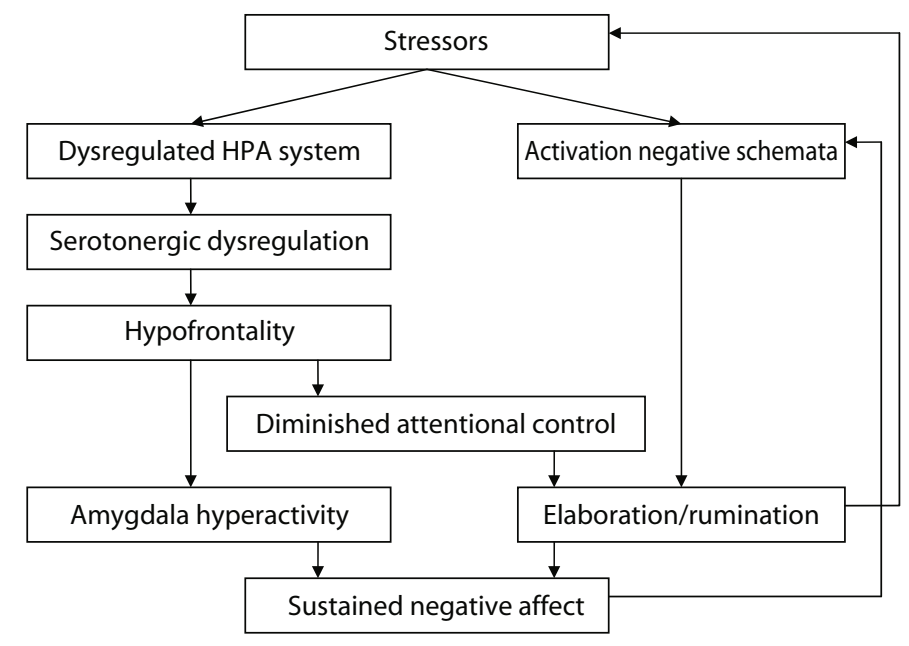

Biological Component

Cognitive Component

Figure 1. A schematic outline of the link between biological and cognitive vulnerability for recurrent depression.

compared with controls, higher and prolonged amygdala activation when asked to temporarily increase their negative affect (Ray et al., 2005). It is important to mention that we make a clear distinction between processes and products, as proposed by Ingram, Miranda, and Segal (1998). Attentional control, as measured by experimental tasks, is considered a process influencing products such as rumination, measured by responses in questionnaires. Although the definition of rumination refers to a process, we differentiate between underlying information processing related to neurobiological functioning and the content and style of thinking, which is the end product of these processes.

On the basis of this framework, we make the following specific assumptions: Episodes of depression are associated with increasing attentional impairments that remain present after remission. These attentional impairments are most pronounced in the processing of negative information after confrontation with stressors (these can be internal-e.g., remembering a distressing event - or external-e.g., social rejection), where individuals have difficulty disengaging their attention from negative emotional material once this has entered the focus of attention. We posit that attentional bias for negative information is not merely an epiphenomenon of depression but an important etiological and maintaining factor. This idea is based on the findings that (1) prospective research shows that the presence of attentional bias for negative information can, in interaction with stress, magnify depressive symptoms; (2) research has shown that interrupting prefrontal control, causing a lateralized frontal brain activity pattern characteristic for depressed people using rTMS, causes mood-congruent attentional impairments in normal individuals similar to those observed in depressed individuals; and (3) experimental manipulation of attentional bias influences depressive symptoms.

There are several testable predictions that can be derived from our account. First, in our view, attentional control under conditions of negative mood or in the presence of stress is crucial to being able to inhibit emotional responding and reorient attention to task-relevant or more positive information. Note that cognitive reappraisal is also crucially dependent on these aspects of attentional control (Ochsner et al., 2002). The attentional impairment observed in depression acts as a gateway, related to impaired inhibition of negative material and thus increased negative material in working memory, that in the long run fuels negative beliefs and schemas (see the arrows leading from elaboration/rumination back to negative schemata in Figure 1). Second, because experimental studies in at-risk individuals and dysphoric individuals fail to show an attentional bias in all individuals, we do not posit that attentional factors are necessarily implicated in the etiology of all individuals who develop depressive episodes. However, with increasing depressive episodes, attentional processes will become increasingly important as regulatory control diminishes. In a recent event-related potential study, it was indeed found that electrophysiological brain activity markers of deficits in cognitive control increase with each depressive episode and persist after symptom remission, suggesting that successive depressive episodes leave a "scar" on cognitive control processes (Vanderhasselt \& De Raedt, 2009). The detrimental effect of these deficient control processes on real life stressors is nicely illustrated in a study by Hooley et al. (2009). Recovered individuals with a history of major depression were scanned while they heard praising, critical, and neutral comments from their own mothers. The groups showed no differences in selfreported mood and showed similar mood changes after being praised or criticized. However, formerly depressed participants responded to criticism with greater amygdala activation, and less activation in the DLPFC and ACC, than did healthy controls. The fact that the recruitment of cognitive control remains deficient after full recovery is further confirmation that abnormalities in corticolimbic activation independent of mood state are a vulnerability factor for depression. 
Our framework provides a useful theoretical explanation for several innovative clinical interventions deemed successful in reducing relapse in formerly depressed patients. Given the dynamic interplay of risk factors, interventions can be successful by targeting one or more of the mechanisms that we have postulated because of reciprocal interactions with other risk factors. One clinical intervention currently widely under investigation is mindfulness-based cognitive therapy (MBCT). MBCT can be conceived as attentional control training (Baer, 2003) with an influence on DLPFC activity (for a review, see Cahn \& Polich, 2006), attentional control (Jha, Krompinger, \& Baime, 2007), and ruminative thinking (Ramel, Goldin, Carmona, \& McQuaid, 2004). Second, over the last years, rTMS over the DLPFC has emerged as a promising treatment procedure for MDD (Avery et al., 2006; Bortolomasi et al., 2007). Research is indicative of the effectiveness of multisession rTMS in reducing depressive symptoms, by influencing brain activity and increasing attentional control (Vanderhasselt, De Raedt, Leyman, \& Baeken, 2009). Finally, emerging research suggests that the therapeutic effect of antidepressant medication is related to changes in cognitive processing of emotional information (see Browning, Holmes, \& Harmer, 2010, in this issue). These findings are also in line with the causal relation between attention and depressive symptoms suggested in our framework.

However, to optimize treatments it could be beneficial to combine biological and psychological treatment options. On the basis of our framework, an important therapeutic aim would be to restore stress reactivity. Interventions should be tailored to facilitate emotion regulation, making it possible to adaptively cope by down-regulating negative, distressing emotions after confrontation with emotionarousing situations. Whereas nowadays cognitive interventions are aimed at altering dysfunctional cognitions, these therapies could be supplemented by techniques to influence deficient processing of these cognitions. In this way, trait vulnerabilies might also be treated, which might lead to decreased relapse rates.

Clearly, in our present knowledge there are several limitations that provide important new avenues for investigation. It is noteworthy that the effect size of attentional impairments in depression is often small to moderate. This could lead one to doubt whether attentional bias can be considered a process involved in important ways in the etiology and maintenance of depression. However, we think that attentional impairments can have quite substantial effects on depression, through its interaction with other cognitive processes (rumination, inhibition, memory) and life stress, causing effects on emotional reactivity. Moreover, we mainly consider the influence of attentional control on rumination. However, we cannot exclude the possibility that the reverse effect is present as well, with ruminative responding directly causing attentional bias. At present, there is no research on the latter possibility, so we decided not to include it in our framework. Finally, general attention deficits and valencespecific attentional impairments have been investigated in separate studies. Therefore, the available data does not allow us to be highly specific about the exact role that each of these factors plays in depression. Moreover, the influence of processing positive stimuli might also be an important factor related to vulnerability, because it might be a resilience factor related to the way people can recover from negative moods. Again, this seems a fruitful area for further research.

Another important issue to consider is the specificity of our framework for depression. Although our framework is based on depression-specific research, there is clearly an overlap between depression and anxiety-related vulnerability factors, at both the cognitive and biological levels. This is not surprising, considering the high comorbidity rates between depression and anxiety. Although anxiety is also characterized by attentional bias toward negative information, the nature of the attentional bias between anxiety and depression seems different in several ways; that is, attentional bias in anxiety is typically relatively automatic in nature and short-lived (stimulus presentation durations $<1,000 \mathrm{msec}$ ). After this initial attentional response, anxious individuals are able to disengage attention from threat and sometimes even show attentional avoidance of threat. Depression is clearly associated with an attentional bias at later stages of information processing with more sustained attentional control impairments. These differences in the nature of attentional bias are presumably related to a different influence of attentional bias in anxiety and depression. In anxiety, initial attentional bias may contribute to the initial stress reactivity to threatening information, whereas attentional bias in depression is related to prolonged processing of negative material and impaired emotion regulation. Empirical research is required to examine the shared and differential effects of attentional bias in depression versus anxiety.

An important aim of our framework is to stimulate further integrative hypothesis-driven research efforts to gain a deeper understanding of the working mechanisms of the development of depression. The ultimate goal is to stimulate translational research to improve the effectiveness of interventions by tailoring them to account for individual differences in underlying processes.

\section{AUTHOR NOTE}

We thank Jan De Houwer and Gilles Pourtois for their thoughtful comments on an earlier version of the manuscript. Correspondence concerning this article should be addressed to R. De Raedt, Department of Experimental Clinical and Health Psychology, Ghent University, Henri Dunantlaan 2, B-9000 Ghent, Belgium (e-mail: rudi.deraedt@ ugent.be).

\section{REFERENCES}

Algom, D., Chajut, E., \& Lev, S. (2004). A rational look at the emotional Stroop phenomenon: A generic slowdown, not a Stroop effect. Journal of Experimental Psychology: General, 133, 323-338.

AMERICAN PSyChiatric Association (2000). Diagnostic and statistical manual of mental disorders (text revision). Washington, DC: Author. Avery, D. H., Holtzheimer, P. E., 3RD, Fawaz, W., Russo, J., NeuMAIER, J., DunNer, D. L., ET AL. (2006). A controlled study of repetitive transcranial magnetic stimulation in medication-resistant major depression. Biological Psychiatry, 59, 187-194.

Baeken, C., De Raedt, R., Bossuyt, A., Van Hove, C., Mertens, J., DobBeleir, A., ET AL. (2010). The neurobiological impact of 
$H F-r T M S$ treatment on post-synaptic serotonin type ${ }_{2 A}$ receptor binding in medication-resistant unipolar depressed patients of the melancholic subtype: A ${ }^{123}$ I-5-I-R91150 SPECT imaging study. Manuscript submitted for publication.

BAER, R. A. (2003). Mindfulness training as a clinical intervention: A conceptual and empirical review. Clinical Psychology: Science \& Practice, 10, 125-143.

BARDEN, N. (2004). Implication of the hypothalamic-pituitary-adrenal axis in the physiopathology of depression. Journal of Psychiatry \& Neuroscience, 29, 185-193.

Beauregard, M., Lévesque, J., \& Bourgouin, P. (2001). Neural correlates of conscious self-regulation of emotion. Journal of Neuroscience, 21, 6993-7000.

Beck, A. T. (1967). Depression: Causes and treatment. Philadelphia: University of Pennsylvania Press.

Beevers, C. G., \& Carver, C. S. (2003). Attentional bias and mood persistence as prospective predictors of dysphoria. Cognitive Therapy \& Research, 27, 619-637.

Beevers, C. G., Wells, T. T., Ellis, A. J., \& McGeary, J. E. (2009). Associations of the serotonin transporter gene promoter region (5-HTTLPR) polymorphism with biased attention for emotional stimuli. Journal of Abnormal Psychology, 118, 670-681.

Beevers, C. G., Wells, T. T., \& Miller, I. W. (2007). Predicting response to depression treatment: The role of negative cognition. Journal of Consulting \& Clinical Psychology, 75, 422-431.

Bethea, C. L., Streicher, J. M., Coleman, K., Pau, F. K. Y., Moessner, R., \& Cameron, J. L. (2004). Anxious behavior and fenfluramine-induced prolactin secretion in young rhesus macaques with different alleles of the serotonin reuptake transporter polymorphism (5HTTLPR). Behavior Genetics, 34, 295-307.

Bhagwagar, Z., Cowen, P. J., Goodwin, G. [M.], \& Harmer, C. J. (2004). Normalization of enhanced fear recognition by acute SSRI treatment in subjects with a previous history of depression. American Journal of Psychiatry, 161, 166-168.

BhagWagar, Z., HAFIZI, S., \& CowEN, P. J. (2003). Increase in concentration of waking salivary cortisol in recovered patients with depression. American Journal of Psychiatry, 160, 1890-1891.

Bhagwagar, Z., Rabiner, E. A., Sargent, P. A., Grasby, P. M., \& Cowen, P. J. (2004). Persistent reduction in brain serotonin1A receptor binding in recovered depressed men measured by positron emission tomography with (11C)WAY-100635. Molecular Psychiatry, 9, 386-392.

BooIJ, L., \& VAN DER DoEs, A. J. W. (2007). Cognitive and serotonergic vulnerability to depression: Convergent findings. Journal of Abnormal Psychology, 116, 86-94.

Bortolomasi, M., Minelli, A., Fuggetta, G., Perini, M., ComenCini, S., Fiaschi, A., \& Manganotti, P. (2007). Long-lasting effects of high frequency repetitive transcranial magnetic stimulation in major depressed patients. Psychiatry Research, 150, 181-186.

Bower, G. H. (1981). Mood and memory. American Psychologist, 36, 129-148.

Bradley, B. P., MogG, K., \& LeE, S. C. (1997). Attentional biases for negative information in induced and naturally occurring dysphoria. Behaviour Research \& Therapy, 35, 911-927.

Bradley, B. P., Mogg, K., Millar, N., Bonham-Carter, C., FerGusson, E., Jenkins, J., \& PARR, M. (1997). Attentional biases for emotional faces. Cognition \& Emotion, 11, 25-42.

Bradley, B. P., Mogg, K., \& Williams, R. (1995). Implicit and explicit memory for emotion-congruent information in clinical depression and anxiety. Behaviour Research \& Therapy, 33, 755-770.

Browning, M., Holmes, E. A., \& Harmer, C. J. (2010). The modification of attentional bias to emotional information: A review of the techniques, mechanisms, and relevance to emotional disorders. Cognitive, Affective, \& Behavioral Neuroscience, 10, 8-20.

Bush, G., LuU, P., \& Posner, M. I. (2000). Cognitive and emotional influences in anterior cingulate cortex. Trends in Cognitive Sciences, 4, 215-222.

Butler, A. C., Hokanson, J. E., \& Flynn, H. A. (1994). A comparison of self-esteem lability and low trait self-esteem as vulnerability factors for depression. Journal of Personality \& Social Psychology, 66, $166-177$.

CAHn, B. R., \& Polich, J. (2006). Meditation states and traits: EEG, ERP, and neuroimaging studies. Psychological Bulletin, 132, 180-211.
Carver, C. S., Johnson, S. L., \& Joormann, J. (2008). Serotonergic function, two-mode models of self-regulation, and vulnerability to depression: What depression has in common with impulsive aggression. Psychological Bulletin, 134, 912-943.

Caseras, X., Garner, M., Bradley, B. P., \& Mogg, K. (2007). Biases in visual orienting to negative and positive scenes in dysphoria: An eye movement study. Journal of Abnormal Psychology, 116, 491-497.

Caspi, A., Sugden, K., Moffitt, T. E., Taylor, A., Craig, I. W., HarRINGTON, H., ET AL. (2003). Influence of life stress on depression: Moderation by a polymorphism in the 5-HTT gene. Science, 301, 386-389.

Cave, K. R., \& Batty, M. J. (2006). From searching for features to searching for threat: Drawing the boundary between preattentive and attentive vision. Visual Cognition, 14, 629-646.

Clark, D. A., Beck, A. T., \& Alford, B. A. (1999). Scientific foundations of cognitive theory and therapy of depression. Hoboken, NJ: Wiley.

Cools, R., RoberTs, A. C., \& Robbins, T. W. (2007). Serotoninergic regulation of emotional and behavioural control processes. Trends in Cognitive Sciences, 12, 31-40.

Dandeneau, S. D., \& Baldwin, M. W. (2004). The inhibition of socially rejecting information among people with high versus low selfesteem: The role of attentional bias and the effects of bias reduction training. Journal of Social \& Clinical Psychology, 23, 584-602.

Dandeneau, S. D., Baldwin, M. W., Baccus, J. R., Sakellaropoulo, M., \& Pruessner, J. C. (2007). Cutting stress off at the pass: Reducing vigilance and responsiveness to social threat by manipulating attention. Journal of Personality \& Social Psychology, 93, 651-666.

Dannlowski, U., Ohrmann, P., Bauer, J., Deckert, J., Hohoff, C., KUGEL, H., ET AL. (2008). 5-HTTLPR biases amygdala activity in response to masked facial expressions in major depression. Neuropsychopharmacology, 33, 418-424.

Davidson, R. J., Pizzagalli, D., Nitschee, J. B., \& Putnam, K. M. (2002). Depression: Perspectives from affective neuroscience. Annual Review of Psychology, 53, 545-574.

Denny, E. B., \& HunT, R. R. (1992). Affective valence and memory in depression: Dissociation of recall and fragment recognition. Journal of Abnormal Psychology, 101, 175-180.

Derryberry, D., \& ReED, M. A. (2002). Anxiety-related attentional biases and their regulation by attentional control. Journal of Abnormal Psychology, 111, 225-236.

De Ruiter, C., \& Brosschot, J. F. (1994). The emotional Stroop interference effect in anxiety: Attentional bias or cognitive avoidance? Behaviour Research \& Therapy, 32, 315-319.

Donaldson, C., Lam, D., \& Mathews, A. (2007). Attention and rumination in major depression. Behaviour Research \& Therapy, 45, 2664-2678.

Eizenman, M., Yu, L. H., Grupp, L., Eizenman, E., Ellendbogen, M., Gemar, M., \& Levitan, R. D. (2003). A naturalistic visual scanning approach to assess selective attention in major depressive disorder. Psychiatry Research, 118, 117-128.

Ellenbogen, M. A., Schwartzman, A. E., Stewart, J., \& Walker, C.-D. (2002). Stress and selective attention: The interplay of mood, cortisol levels, and emotional information processing. Psychophysiology, 39, 723-732.

Ellis, H. C., \& Ashвrook, P. W. (1988). Resource allocation model of the effects of depressed mood states on memory. In K. Fiedler \& J. Forgas (Eds.), Affect, cognition, and social behaviour (pp. 25-43). Toronto: Hogrefe.

Fales, C. L., Barch, D. M., Rundle, M. M., Mintun, M. A., Snyder, A. Z., Cohen, J. D., ET AL. (2008). Altered emotional interference processing in affective and cognitive-control brain circuitry in major depression. Biological Psychiatry, 63, 377-384.

FIRK, C., \& MARKUS, C. R. (2007). Review: Serotonin by stress interaction: A susceptibility factor for the development of depression? Journal of Psychopharmacology, 21, 538-544.

Fox, E., Russo, R., Bowles, R. J., \& Dutton, K. (2001). Do threatening stimuli draw or hold visual attention in subclinical anxiety? Journal of Experimental Psychology: General, 130, 681-700.

Gardner, K. L., Thrivikraman, K. V., Lightman, S. L., Plotsky, P. M., \& Lowry, C. A. (2005). Early life experience alters behavior during social defeat: Focus on serotonergic systems. Neuroscience, 136, 181-191.

Gituin, M. J. (2009). Pharmacotherapy and other somatic treatments 
for depression. In I. H. Gotlib \& C. L. Hammen (Eds.), Handbook of depression (2nd ed., pp. 554-585). New York: Guilford.

Goeleven, E., De Raedt, R., Baert, S., \& Koster, E. H. W. (2006). Deficient inhibition of emotional information in depression. Journal of Affective Disorders, 93, 149-157.

Gold, P. W., \& Chrousos, G. P. (2002). Organization of the stress system and its dysregulation in melancholic and atypical depression: High vs low CRH/NE states. Molecular Psychiatry, 7, 254-275.

Goodwin, R. D., Jacobi, F., Bittner, A., \& Wittchen, H. (2006). Epidemiology of mood disorders. In D. J. Stein, D. J. Kupfer, \& A. F. Schatzberg (Eds.), Text book of mood disorders (pp. 33-54). Arlington, VA: American Psychiatric Publishing.

Gotlib, I. H., Joormann, J., Minor, K. L., \& Hallmayer, J. (2008). HPA axis reactivity: A mechanism underlying the associations among 5-HTTLPR, stress, and depression. Biological Psychiatry, 63, 847851.

Gotlib, I. H., Kasch, K. L., Traill, S. K., Joormann, J., Arnow, B. A., \& JoHnson, S. L. (2004). Coherence and specificity of informationprocessing biases in depression and social phobia. Journal of Abnormal Psychology, 113, 386-398.

Gotlib, I. H., Krasnoperova, E., Yue, D. N., \& Joormann, J. (2004). Attentional bias for negative interpersonal stimuli in clinical depression. Journal of Abnormal Psychology, 113, 127-135.

Gotlib, I. H., Mclachlan, A. L., \& Katz, A. N. (1988). Biases in visual attention in depressed and nondepressed individuals. Cognition \& Emotion, 2, 185-200.

Hankin, B. L., Abramson, L. Y., Miller, N., \& Haeffel, G. L. (2004). Cognitive vulnerability-stress theories of depression: Examining affective specificity in the prediction of depression versus anxiety in three prospective studies. Cognitive Therapy \& Research, 28, 309-345.

Hansen, C. H., \& HANSEN, R. D. (1988). Finding the face in the crowd: An anger superiority effect. Journal of Personality \& Social Psychology, 54, 917-924.

Hariri, A. R., \& Holmes, A. (2006). The serotonin transporter and the genetics of affect regulation. Trends in Cognitive Sciences, 10, 182-191.

Harmer, C. J., Mackay, C. E., Reid, C. B., Cowen, P. J., \& GoodWIN, G. M. (2006). Antidepressant drug treatment modifies the neural processing of nonconscious threat cues. Biological Psychiatry, 59, 816-820.

Harmer, C. J., Shelley, N. C., Cowen, P. J., \& Goodwin, G. M. (2004). Increased positive versus negative affective perception and memory in healthy volunteers following selective serotonin and norepinephrine reuptake inhibition. American Journal of Psychiatry, 161, 1256-1263.

Heim, C., \& Nemeroff, C. B. (2001). The role of childhood trauma in the neurobiology of mood and anxiety disorders: Preclinical and clinical studies. Biological Psychiatry, 49, 1023-1039.

Herbert, J., Goodyer, I. M., Grossman, A. B., Hastings, M. H., DE Kloet, E. R., Lightman, S. L., et Al. (2006). Do corticosteroids damage the brain? Journal of Neuroendocrinology, 18, 393-411.

Hertel, P. T., \& Rude, S. S. (1991). Depressive deficits in memory: Focusing attention improves subsequent recall. Journal of Experimental Psychology: General, 120, 301-309.

Hill, A. B., \& DutTon, F. (1989). Depression and selective attention to self-esteem threatening words. Personality \& Individual Differences, 10, $915-917$

Hollon, S. D., \& Dimidjian, S. (2009). Cognitive and behavioral treatment of depression. In I. H. Gotlib \& C. L. Hammen (Eds.), Handbook of depression (2nd ed., pp. 586-603). New York: Guilford.

Holmes, A. J., \& Pizzagalli, D. A. (2008). Response conflict and frontocingulate dysfunction in unmedicated participants with major depression. Neuropsychologia, 46, 2904-2913.

Holsboer, F. (1995). Neuroendocrinology of mood disorders. In F. E. Bloom \& D. J. Kupfer (Eds.), Psychopharmacology: The fourth generation of progress (pp. 957-969). New York: Raven Press.

Hooley, J. M., Gruber, S. A., Parker, H. A., Guillaumot, J., Rogowska, J., \& Yurgelun-Todd, D. A. (2009). Cortico-limbic response to personally challenging emotional stimuli after complete recovery from depression. Psychiatry Research: Neuroimaging, 171, 106-119.

Hopfinger, J. B., Buonocore, M. H., \& Mangun, G. R. (2000). The neural mechanisms of top-down attentional control. Nature Neuroscience, 3, 284-291.
Ingram, R. E., Miranda, J., \& Segal, Z. V. (1998). Cognitive vulnerability to depression. New York: Guilford.

Ingram, R. E., \& Siegle, G. J. (2009). Methodological issues in the study of depression. In I. H. Gotlib \& C. L. Hammen (Eds.), Handbook of depression (2nd ed., pp. 69-92). New York: Guilford.

Jha, A. P., Krompinger, J., \&, Baime, M. J. (2007). Mindfulness training modifies subsystems of attention. Cognitive, Affective, \& Behavioral Neuroscience, 7, 109-119.

Johnstone, T., Van Reekum, C. M., Urry, H. L., Kalin, N. H., \& DAVIDSON, R. J. (2007). Failure to regulate: Counterproductive recruitment of top-down prefrontal-subcortical circuitry in major depression. Journal of Neuroscience, 27, 8877-8884.

Joormann, J. (2004). Attentional bias in dysphoria: The role of inhibitory processes. Cognition \& Emotion, 18, 125-147.

Joormann, J., \& Gotlib, I. H. (2007). Selective attention to emotional faces following recovery from depression. Journal of Abnormal Psychology, 116, 80-85

JoORMANN, J., \& GotLIB, I. H. (2008). Updating the contents of working memory in depression: Interference from irrelevant negative material. Journal of Abnormal Psychology, 117, 182-192.

Joormann, J., Talbot, L., \& Gotlib, I. H. (2007). Biased processing of emotional information in girls at risk for depression. Journal of Abnormal Psychology, 116, 135-143.

Joormann, J., Yoon, K. L., \& Zetsche, U. (2007). Cognitive inhibition in depression. Applied \& Preventive Psychology, 12, 128-139.

Karparova, S. P., Kersting, A., \& Suslow, T. (2007). Deployment of attention in clinical depression during symptom remission. Scandinavian Journal of Psychology, 48, 1-5.

Keck, M. E., \& Holsboer, F. (2001). Hyperactivity of CRH neuronal circuits as a target for therapeutic interventions in affective disorders. Peptides, 22, 835-844.

Kellough, J., Beevers, C. G., Ellis, A., \& Wells, T. T. (2008). Time course of selective attention in depressed young adults: An eye tracking study. Behavior Research \& Therapy, 11, 1238-1243.

Kessing, L. V., Hansen, M. G., Andersen, P. K., \& Angst, J. (2004). The predictive effect of episodes on the risk of recurrence in depressive and bipolar disorders-A life-long perspective. Acta Psychiatrica Scandinavica, 109, 339-344.

Kingsley, R. E. (2000). Concise text of neuroscience (2nd ed.). Philadelphia: Lippincott Williams \& Wilkins.

Koster, E. H. W., De Raedt, R., Goeleven, E., Franck, E., \& CromBEZ, G. (2005). Mood-congruent attentional bias in dysphoria: Maintained attention to and impaired disengagement from negative information. Emotion, 5, 446-455.

Koster, E. H. W., De Raedt, R., Leyman, L., \& De Lissnyder, E. (2010). Mood-congruent attention and memory bias in dysphoria: Exploring the coherence among information-processing biases. $\mathrm{Be}$ haviour Research \& Therapy, 48, 219-225.

Koster, E. H. W., De Raedt, R., Tibboel, H., De Jong, P. J., \& VerSCHUERE, B. (2009). Negative information enhances the attentional blink in dysphoria. Depression \& Anxiety, 26, E16-E22.

Lanfumey, L., Mongeau, R., Cohen-Salmon, C., \& Hamon, M. (2008). Corticosteroid-serotonin interactions in the neurobiological mechanisms of stress-related disorders. Neuroscience \& Biobehavioral Reviews, 32, 1174-1184.

Levinson, D. F. (2009). Genetics of major depression. In I. H. Gotlib \& C. L. Hammen (Eds.), Handbook of depression (2nd ed., pp. 165186). New York: Guilford.

Leyman, L., De Raedt, R., Schacht, R., \& Koster, E. H. W. (2007). Attentional biases for angry faces in unipolar depression. Psychological Medicine, 37, 393-402.

Leyman, L., De Raedt, R., Vaeyens, R., \& Phillipaerts, R. (in press). Attention for emotional facial expressions in dysphoria: An eye-movement registration study. Cognition \& Emotion.

Leyman, L., De Raedt, R., Vanderhasselt, M. A., \& Baeken, C. (2009). Influence of HF-rTMS over the dorsolateral prefrontal cortex on the inhibition of emotional information in healthy volunteers. Psychological Medicine, 39, 1019-1028.

Leyman, L., De Raedt, R., Vanderhasselt, M. A., \& Baeken, C. (in press). Effects of repetitive transcranial magnetic stimulation of the dorsolateral prefrontal cortex on the attentional processing of emotional information in major depression: A pilot study. Psychiatry Research. 
Leyton, M., Young, S. N., Blier, P., Ellenbogen, M. A., Palmour, R. M., Ghadirian, A. M., \& Benkelfat, C. (1997). The effect of tryptophan depletion on mood in medication-free former patients with major affective disorder. Neuropsychopharmacology, 16, 294-297.

López, J. F., Liberzon, I., VÁzquez, D. M., Young, E. A., \& WatSON, S. J. (1999). Serotonin 1A receptor messenger RNA regulation in the hippocampus after acute stress. Biological Psychiatry, 45, 934-937.

MacDonald, A. W., III, Cohen, J. D., Stenger, V. A., \& Carter, C. S. (2000). Dissociating the role of the dorsolateral prefrontal and anterior cingulate cortex in cognitive control. Science, 288, 1835-1838.

MacLeod, C., \& HaGAN, R. (1992). Individual differences in the selective processing of threatening information and emotional responses to a stressful life event. Behaviour Research \& Therapy, 30, 151-161.

MacLeod, C., Koster, E. H. W., \& Fox, E. (2009). Whither cognitive bias modification research: A commentary on the special section. Journal of Abnormal Psychology, 118, 89-99.

MacLeod, C., Mathews, A., \& Tata, P. (1986). Attentional bias in emotional disorders. Journal of Abnormal Psychology, 95, 15-20.

Macleod, C., Rutherford, E. M., Campbell, L., Ebsworthy, G., \& Holker, L. (2002). Selective attention and emotional vulnerability: Assessing the causal basis of their association through the experimental manipulation of attentional bias. Journal of Abnormal Psychology, 111, 107-123.

Mann, J. J., Brent, D. A., \& Arango, V. (2001). The neurobiology and genetics of suicide and attempted suicide: A focus on the serotonergic system. Neuropsychopharmacology, 24, 467-477.

Mathews, A., Ridgeway, V., \& Williamson, D. A. (1996). Evidence for attention to threatening stimuli in depression. Behaviour Research \& Therapy, 34, 695-705.

Matthews, G. R., \& Antes, J. R. (1992). Visual attention and depression: Cognitive biases in the eye fixation of the dysphoric and nondepressed. Cognitive Therapy \& Research, 16, 359-371.

MaYberg, H. S. (1997). Limbic-cortical dysregulation: A proposed model of depression. Journal of Neuropsychiatry \& Clinical Neurosciences, 9, 471-481.

MAYBERG, H. S. (2002). Mapping mood: An evolving emphasis on frontal-limbic interactions. In D. T. Stuss \& R. T. Knight (Eds.), Principles of frontal lobe function (pp. 376-391). New York: Oxford University Press.

Mayberg, H. S. (2003). Positron emission tomography imaging in depression: A neural systems perspective. Neuroimaging Clinics of North America, 13, 805-815.

McCaвe, S. B., \& Gotlib, I. H. (1995). Selective attention and clinical depression: Performance on a deployment-of-attention task. Journal of Abnormal Psychology, 104, 241-245.

McCabe, S. B., Gotlib, I. H., \& Martin, R. (2000). Cognitive vulnerability for depression: Deployment of attention as a function of history of depression and current mood state. Cognitive Therapy \& Research, 24, 427-444.

McCabe, S. B., \& Toman, P. E. (2000). Stimulus exposure duration in a deployment-of-attention task: Effects on dysphoric, recently dysphoric and nondysphoric individuals. Cognition \& Emotion, 14, 125-142.

McEwen, B. S. (2000). Allostasis and allostatic load: Implications for neuropsychopharmacology. Neuropsychopharmacology, 22, 108-124.

Merens, W., Van der Does, A. J. W., \& Spinhoven, P. (2007). The effects of serotonin manipulations on emotional information processing and mood. Journal of Affective Disorders, 103, 43-62.

Mizoguchi, K., Shoji, H., Ikeda, R., TanaKa, Y., \& Tabira, T. (2008). Persistent depressive state after chronic stress in rats is accompanied by HPA axis dysregulation and reduced prefrontal dopaminergic neurotransmission. Pharmacology Biochemistry \& Behavior, 91, 170-175.

Mizoguchi, K., Yuzurihara, M., Ishige, A., Sasaki, H., Chui, D.-H., \& TABIRA, T. (2001). Chronic stress differentially regulates glucocorticoid negative feedback response in rats. Psychoneuroendocrinology, 26, 443-459.

Mizoguchi, K., Yuzurihara, M., Ishige, A., Sasaki, H., \& Tabira, T. (2002). Chronic stress impairs rotarod performance in rats: Implications for depressive state. Pharmacology, Biochemistry \& Behaviour, 71, 79-84.

MogG, K., \& Bradley, B. P. (2005). Attentional bias in generalized anxiety disorder versus depressive disorder. Cognitive Therapy \& Research, 29, 29-45.

Mogg, K., Bradley, B. P., \& Williams, R. (1995). Attentional bias in anxiety and depression: The role of awareness. British Journal of Clinical Psychology, 34, 17-36.

MogG, K., Millar, N., \& Bradley, B. P. (2000). Biases in eye movements to threatening facial expressions in generalized anxiety disorder and depressive disorder. Journal of Abnormal Psychology, 109, 695-704.

Monroe, S. M., \& Harkness, K. L. (2005). Life stress, the "kindling" hypothesis, and the recurrence of depression: Considerations from a life stress perspective. Psychological Review, 112, 417-445.

Moulds, M. L., Kandris, E., Williams, A. D., Lang, T., YaP, C., \& HoFfMEISTER, K. (2008). An investigation of the relationship between cognitive reactivity and rumination. Behavior Therapy, 39, 65-71.

Murphy, F. C., Sahakian, B. J., Rubinsztein, J. S., Michael, A., Rogers, R. D., Robbins, T. W., \& PAYkel, E. S. (1999). Emotional bias and inhibitory control processes in mania and depression. Psychological Medicine, 29, 1307-1321.

Nolen-Hoeksema, N. (1991). Responses to depression and their effects on the duration of depressive episodes. Journal of Abnormal Psychology, 100, 569-582.

Nolen-Hoeksema, N. (2000). The role of rumination in depressive disorders and mixed anxiety/depressive symptoms. Journal of Abnormal Psychology, 109, 504-511.

Nolen-Hoeksema, N., Morrow, J., \& Fredrickson, B. L. (1993). Response styles and the duration of episodes of depressed mood. Journal of Abnormal Psychology, 102, 20-28.

OChSNer, K. N., Bunge, S. A., Gross, J. J., \& Gabrieli, J. D. E. (2002). Rethinking feelings: An fMRI study of the cognitive regulation of emotion. Journal of Cognitive Neuroscience, 14, 1215-1229.

OCHSNER, K. N., \& Gross, J. J. (2008). Cognitive emotion regulation: Insights from social cognitive and affective neuroscience. Current Directions in Psychological Science, 17, 153-158.

O’Toole, S. M., Sekula, L. K., \& Rubin, R. T. (1997). Pituitaryadrenal cortical axis measures as predictors of sustained remission in major depression. Biological Psychiatry, 42, 85-89.

Pariante, C. M., \& Lightman, S. (2008). The HPA axis in major depression: Classical theories and new developments. Trends in Neurosciences, 31, 464-468.

Phan, K. L., Wager, T. D., TaYlor, S. F., \& Liberzon, I. (2004). Functional neuroimaging studies of human emotions. Central Nervous System Spectrums, 9, 258-266.

Phillips, M. L., Drevets, W. C., Rauch, S. L., \& Lane, R. (2003) Neurobiology of emotion perception II: Implication for major psychiatric disorders. Biological Psychiatry, 54, 515-528.

Posner, M. I. (1980). Orienting of attention. Quarterly Journal of Experimental Psychology, 32, 3-25.

Posner, M. I., \& Cohen, Y. (1984). Components of visual attention. In H. Bouma \& D. G. Bouwhuis (Eds.), Attention and performance X: Control of language processes (pp. 531-556). Hillsdale, NJ: Erlbaum.

Ramel, W., Goldin, P. R., Carmona, P. E., \& McQuaid, J. R. (2004). The effects of mindfulness meditation on cognitive processes and af fect in patients with past depression. Cognitive Therapy \& Research, 28, 433-455.

Ray, R. D., Oschner, K. N., Cooper, J. C., Robertson, E. R., GaBRIELI, J. D. E., \& Gross, J. J. (2005). Individual differences in trait rumination and the neural systems supporting cognitive reappraisal. Cognitive, Affective, \& Behavioral Neuroscience, 5, 156-168.

RINCK, M., \& BECKER, E. S. (2005). A comparison of attentional biases and memory biases in women with social phobia and major depression. Journal of Abnormal Psychology, 114, 62-74.

Risch, N., Herrell, R., Lehner, T., Liang, K.-Y., Eaves, L., HoH, J., ET AL. (2009). Interaction between the serotonin transporter gene (5-HTTLPR), stressful life events, and risk of depression: A metaanalysis. Journal of the American Medical Association, 301, 24622471.

Roiser, J. P., Levy, J., Fromm, S., Wang, H. Y., Hasler, G., SahaKIAN, B. J., \& DREvETS, W. C. (2008). The effect of acute tryptophan depletion on the neural correlates of emotional processing in healthy volunteers. Neuropsychopharmacology, 33, 1992-2006.

Rokke, P. D., Arnell, K. M., Koch, M. D., \& Andrews, J. T. (2002). 
Dual task attention deficits in dysphoric mood. Journal of Abnormal Psychology, 111, 370-379.

Ruhé, H. G., Mason, N. S., \& Schene, A. H. (2007). Mood is indirectly related to serotonin, norepinephrine and dopamine levels in humans: A meta-analysis of monoamine depletion studies. Molecular Psychiatry, 12, 331-359.

SAPOLSKY, R. M. (1996). Why stress is bad for your brain. Science, 273, 749-750.

Scher, C. D., Ingram, R. E., \& Segal, Z. V. (2005). Cognitive reactivity and vulnerability: Empirical evaluation of construct activation and cognitive diatheses in unipolar depression. Clinical Psychology Review, 25, 487-510.

Segal, Z. V., Gemar, M. C., \& Williams, S. (1999). Differential cognitive response to a mood challenge following successful cognitive therapy or pharmacotherapy for unipolar depression. Journal of Abnormal Psychology, 108, 3-10.

Seminowicz, D. A., Mayberg, H. S., McIntosh, A. R., Goldapple, K., Kennedy, S., Segal, Z., \& Rafi-Tari, S. (2004). Limbic-frontal circuitry in major depression: A path modeling metanalysis. NeuroImage, 22, 409-418.

Sergerie, K., Chochol, C., \& Armony, J. L. (2008). The role of the amygdala in emotional processing: A quantitative meta-analysis of functional neuroimaging studies. Neuroscience \& Biobehavioral Reviews, 32, 811-830.

Shane, M. S., \& Peterson, J. B. (2007). An evaluation of early and late stage attentional processing of positive and negative information in dysphoria. Cognition \& Emotion, 21, 789-815.

Sheppard, L. C., \& Teasdale, J. D. (2000). Dysfunctional thinking in major depressive disorder: A deficit in metacognitive monitoring? Journal of Abnormal Psychology, 109, 768-776.

Sheppard, L. C., \& Teasdale, J. D. (2004). How does dysfunctional thinking decrease during recovery from major depression? Journal of Abnormal Psychology, 113, 64-71.

Solomon, D. A., Keller, M. B., Leon, A. C., Mueller, T. I., Lavori, P. W., SheA, M. T., ET AL. (2000). Multiple recurrences of major depressive disorder. American Journal of Psychiatry, 157, 229-233.

Suslow, T., Dannlowski, U., Lalee-Mentzel, J., Donges, U.-S., Arolt, V., \& Kersting, A. (2004). Spatial processing of facial emotion in patients with unipolar depression: A longitudinal study. Journal of Affective Disorders, 83, 59-63.

Suslow, T., Junghanns, K., \& ARolt, V. (2001). Detection of facial expressions of emotions in depression. Perceptual \& Motor Skills, 92, 857-868.

TAYlor, J. G., \& Fragopanagos, N. F. (2005). The interaction of attention and emotion. Neural Networks, 18, 353-369.

Teasdale, J. D. (1988). Cognitive vulnerability to persistent depression. Cognition \& Emotion, 2, 247-274.

Teasdale, J. D., Segal, Z. V., \& Williams, J. M. G. (1995). How does cognitive therapy prevent depressive relapse and why should attentional control (mindfulness) training help? An information processing analysis. Behaviour Research \& Therapy, 33, 25-39.

Thase, M. E. (2009). Neurobiological aspects of depression. In I. H. Gotlib \& C. L. Hammen (Eds.), Handbook of depression (2nd ed., pp. 187-217). New York: Guilford.

TITCHENER, E. B. (1908). Lectures on the elementary psychology of feeling and attention. New York: Macmillan.

Treisman, A., \& Souther, J. (1985). Search asymmetry: A diagnostic for preattentive processing of separable features. Journal of Experimental Psychology: General, 114, 285-310.

Uher, R., \& McGuffin, P. (2008). The moderation by the serotonin transporter gene of environmental adversity in the aetiology of mental illness: Review and methodological analysis. Molecular Psychiatry, 13, 131-146.

VAnderhasselt, M. A., \& De RAedt, R. (2009). Impairments in cognitive control persist during remission from depression and are related to the number of past episodes: An event related potentials study. Biological Psychology, 81, 169-176.

Vanderhasselt, M. A., De Raedt, R., Leyman, L., \& Baeken, C. (2009). Acute effects of repetitive transcranial magnetic stimulation on attentional control are related to antidepressant outcomes. Journal of Psychiatry \& Neuroscience, 34, 119-126.

van Praag, H. M., De Kloet, R., \& van Os, J. (2004). Stress, the brain and depression. Cambridge: Cambridge University Press.

Wager, T. D., Davidson, M. L., Hughes, B. L., Lindquist, M. A., \& Ochsner, K. N. (2008). Prefrontal-subcortical pathways mediating successful emotion regulation. Neuron, 59, 1037-1050.

Wells, T. T., \& Beevers, C. G. (in press). Attention training reduces depressive symptoms. Cognition \& Emotion.

Westra, H. A., \& KuIPER, N. A. (1997). Cognitive content specificity in selective attention across four domains of maladjustment. Behaviour Research \& Therapy, 35, 349-365.

Williams, J. M. G., Mathews, A., \& MacLeod, C. (1996). The emotional Stroop task and psychopathology. Psychological Bulletin, 120, 3-24.

Williams, J. M. G., Watts, F. N., MacLeod, C., \& Mathews, A. (1997). Cognitive psychology and emotional disorders (2nd ed.). Chichester, U.K.: Wiley.

Yatham, L. N., Liddle, P. F., Shiah, I.-S., Lam, R. W., Adam, M. J., ZIS, A. P., \& RUTH, T. J. (2001). Effects of rapid tryptophan depletion on brain 5- $\mathrm{HT}_{2}$ receptors: A PET study. British Journal of Psychiatry, 178, 448-453.

Yücel, M., Wood, S. J., Fornito, A., Riffkin, J., Velakoulis, D., \& PANTELIS, C. (2003). Anterior cingulate dysfunction: Implications for psychiatric disorders? Journal of Psychiatry \& Neuroscience, 28, 350-354.

ZALD, D. H. (2003). The human amygdala and the emotional evaluation of sensory stimuli. Brain Research Reviews, 41, 88-123. 


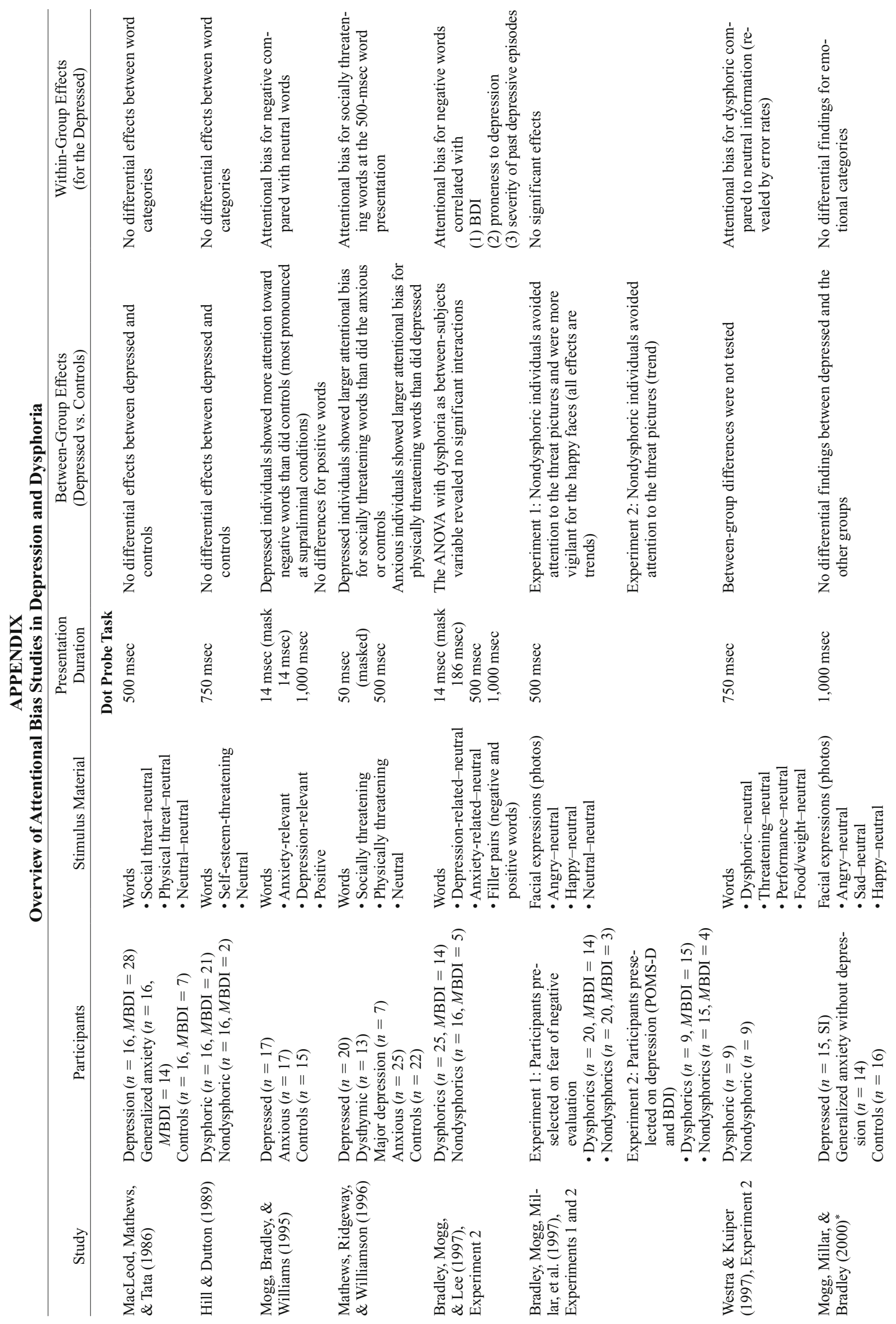




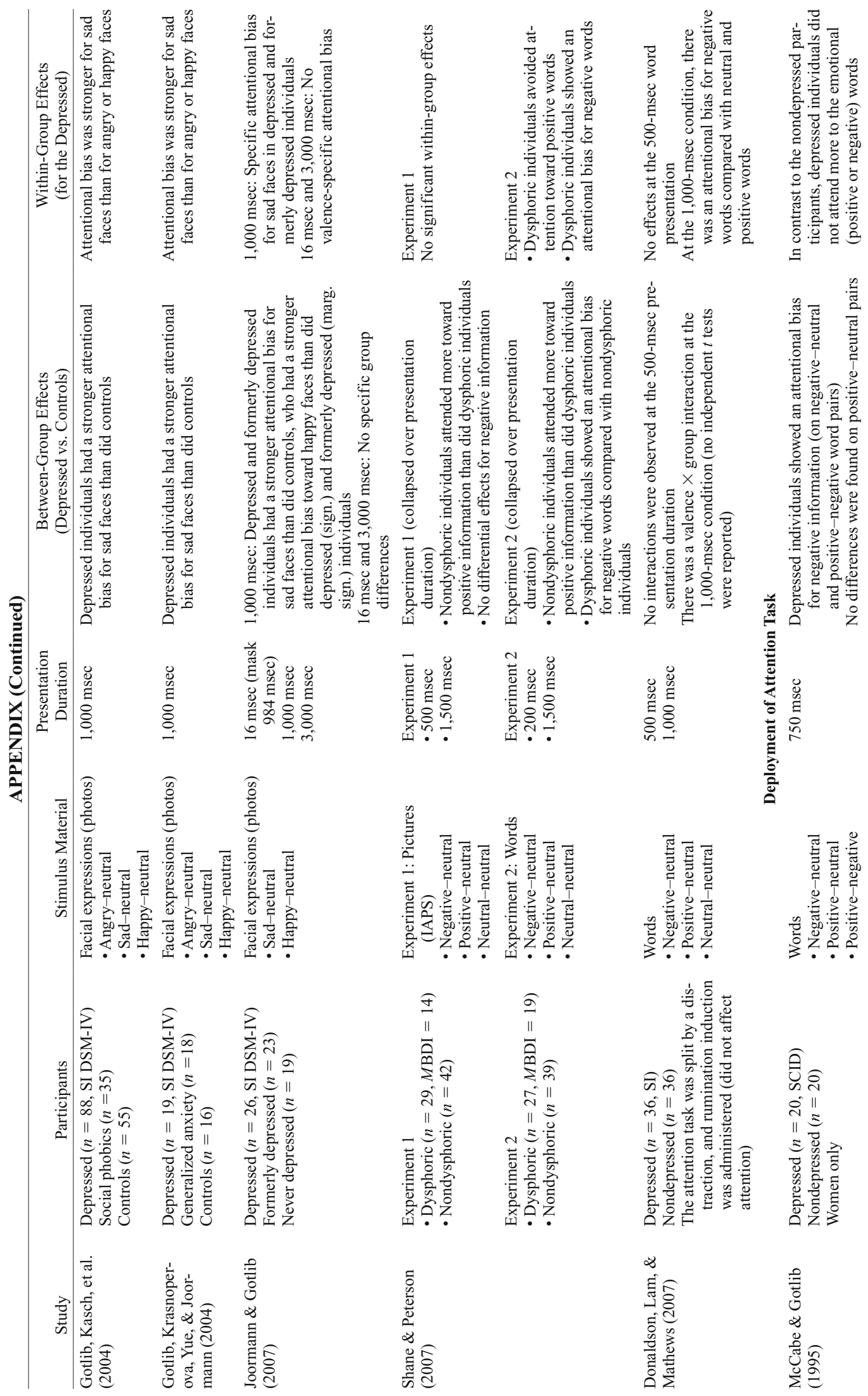




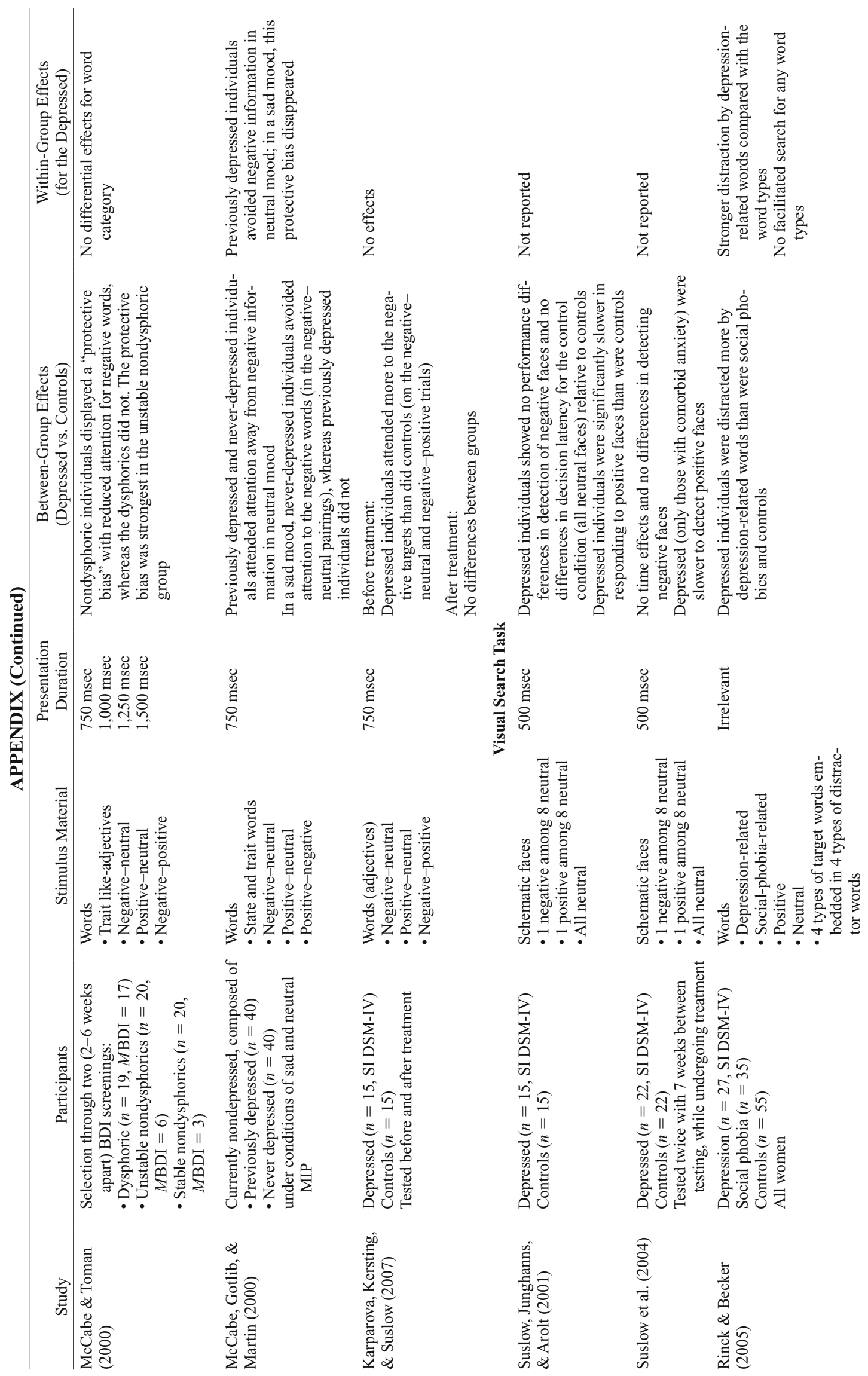




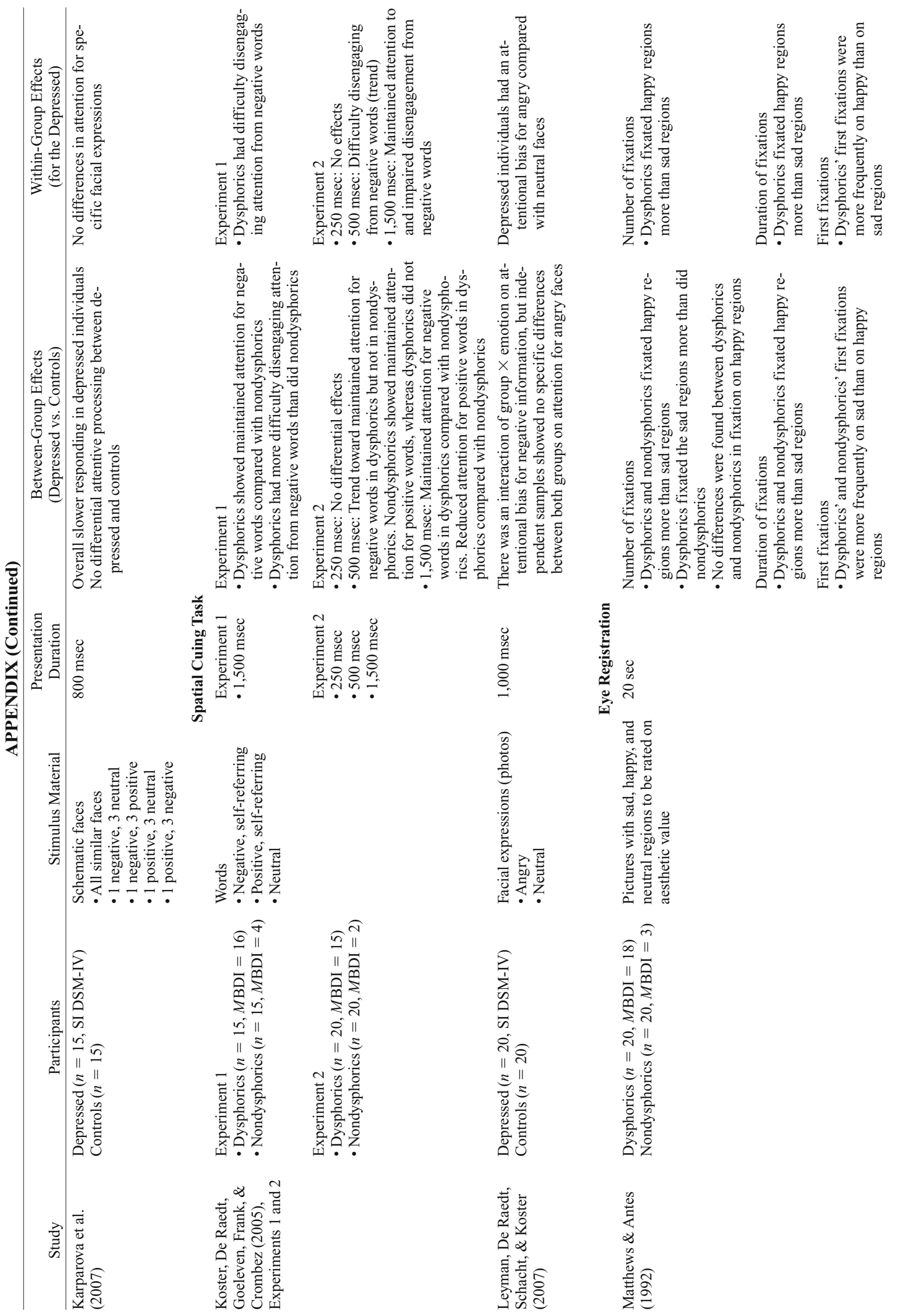




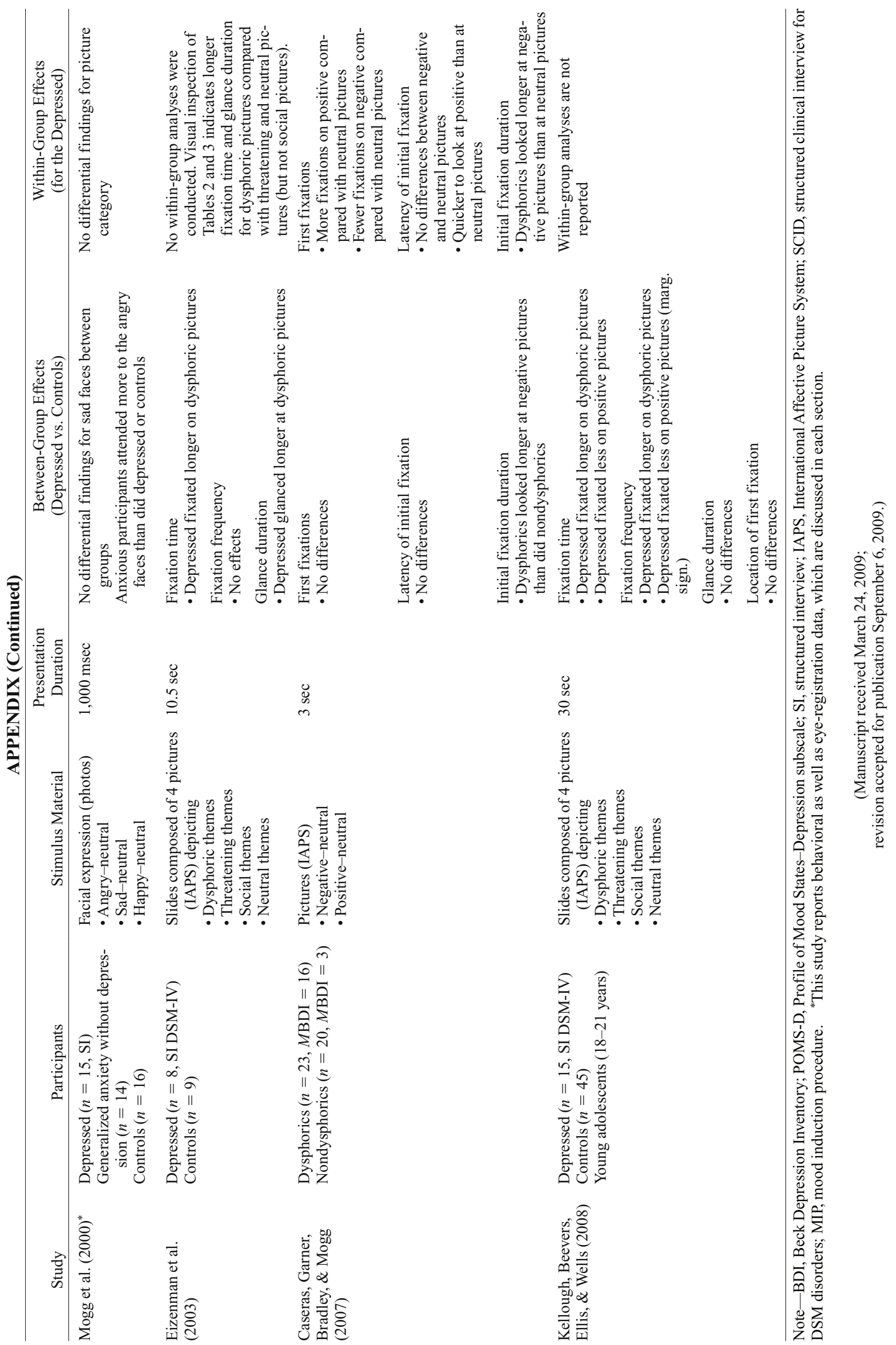

